\title{
Thin film encapsulation for the organic light-emitting diodes display via atomic layer deposition
}

\author{
Yun Lii ${ }^{1}$, Yingfei Xiong ${ }^{2}$, Huizhi Yang ${ }^{3}$, Kun Cao ${ }^{1}$, Rong Chen ${ }^{1, a)}$ (]) \\ ${ }^{1}$ State Key Laboratory of Digital Manufacturing Equipment and Technology, Huazhong University of Science and Technology, Wuhan, Hubei 430074, \\ People's Republic of China; and School of Mechanical Science and Engineering, Huazhong University of Science and Technology, Wuhan, Hubei 430074, \\ People's Republic of China \\ ${ }^{2}$ State Key Laboratory of Digital Manufacturing Equipment and Technology, Huazhong University of Science and Technology, Wuhan, Hubei 430074, \\ People's Republic of China; and China-EU Institute for Clean and Renewable Energy, Huazhong University of Science and Technology, Wuhan, Hubei \\ 430074, People's Republic of China \\ ${ }^{3}$ State Key Laboratory of Digital Manufacturing Equipment and Technology, Huazhong University of Science and Technology, Wuhan, Hubei 430074, \\ People's Republic of China; and School of Optical and Electronic Information, Huazhong University of Science and Technology, Wuhan, Hubei 430074, \\ People's Republic of China \\ a) Address all correspondence to this author. e-mail: rongchen@mail.hust.edu.cn \\ This paper has been selected as an Invited Feature Paper. \\ Received: 28 August 2019; accepted: 9 October 2019
}

Organic light-emitting diodes (OLEDs) have aroused great attention due to the advantages of high luminescent efficiency, fast response time, wide viewing angle, and the compatibility with the flexible electronics. Nevertheless, the organic luminescent materials are vulnerable to environment moisture/oxygen. Thus, how to protect the OLEDs from the ambient moisture/oxygen erosion is of great importance to ensure the stability and reliability. Thin film encapsulation (TFE) via atomic layer deposition (ALD) has emerged as a potential method to meet the encapsulation requirements of OLEDs due to its unique assets. In this review, the challenges of TFE, including pinholes, crystallization, cracks, and overheated, are introduced first. The ALD-based monolayer, composite structures, and hybrid laminates were developed to improve the barrier property, flexibility, and thermal conductivity. Besides, the ALD reactors and processes for TFE are also reviewed. Finally, the challenges remained and future development in the stabilization of OLEDs via ALD are also discussed.

\section{Introduction}

The development of the display industry has experienced different stages from the cathode ray tube [1], liquid crystal display [2], and plasma display panel [3] to the light-emitting diodes (LEDs) [4]. Due to the excellent properties of organic luminescent materials such as high efficiency, high contrast, fast response time, and wide viewing angle, organic LED (OLED) is becoming the dominant trend for the nextgeneration display technology $[5,6]$. Light would emit from the polymer or small organic molecules (such as TPP [7], $\mathrm{Alq}_{3}$ [8], TBADN [9], anthracenes [10]) directly in OLED display $[11,12]$. Besides, the OLED device can be fabricated on plastic substrates, which is compatible with the flexible electronics [13, 14]. However, the organic emitting layer, as well as the metal electrodes, is easy to be eroded by the water and oxygen in the ambient [15], leading to the degradation of the OLEDs. Glass or metal lids were used to encapsulate the devices with the edge area sealed by the ultraviolet curable glue, which presented superior barrier properties. The lack of flexibility made it difficult to be applied to the flexible displays. Hence, thin film encapsulation (TFE) has emerged as an attractive method to fabricate the flexible barriers [16, 17].

For OLED encapsulation, the adhesion and conformality of the barrier films are of great importance to guarantee the reliability and stability. Among various physical vapor deposition (PVD) methods, the magnetron sputtering and ion plating have been developed to address poor adhesion. Yet, these high energy methods often lead to the damage of OLED surfaces. Moreover, the conformality of PVD methods is also hard to be promoted. The chemical vapor deposition (CVD) 
could provide films with stronger adhesion and better conformality than that of PVD. These high-temperature deposition processes are not compatible with the thermal budget of the organic light-emitting layer. Hereby, plasma-enhanced chemical vapor deposition (PE-CVD) has been developed to lower the process temperature and becomes the dominant TFE method. But the unavoidable pinholes on the surfaces [18] lead to moisture permeation into the electrodes and emitting layers, as shown in Fig. 1(I) [19]. At the same time, the thicker layer tends to crystallize [20,21], and the grain boundaries would serve as the pathway for the moisture permeation, as shown in Fig. 1(II). The above issues will lead to the black spots of the light-emitting areas. Thus, the thickness of inorganic barriers needs to be controlled precisely at nanoscale to suppress the pinholes and grain boundaries. Method to solve these issues is to deposit different materials alternatively to suppress the crystallization [22], and the pinholes would be decoupled effectively. On the other hand, the internal stress originated from the increasing thickness of the barrier films as well as the external stress accumulated lead to the crack or delamination of barriers from the OLED surfaces $[23,24,25$, 26], which is shown in Fig. 1(III). In the Barix method invented by Vitex system [27], the polymer is utilized to help decouple the pinholes and release the stress, and the barrier property of the inorganic/organic dyads is equivalent to that of glass lids. Nevertheless, the manufacturing of OLEDs needs to be transferred between different vacuum chambers, making it high cost to be adopted in the large area and high-throughput manufacturing. Besides, the OLED faces serious performance degradation due to heat accumulation that damages the luminescent materials [28], leading to the decrease in the efficiency and lifetime [29, 30,31]. Thus, when designing the encapsulation layer, the following issues need to be considered: (i) the pinhole-decoupled and water-resistant barriers without grain boundaries need to be fabricated to promote the barrier property when applied in the severe conditions with high temperature and high humility; (ii) the overall structure needs to be optimized to release the internal or external stress applied on the barriers, which can promote the mechanical property when applied to flexible OLEDs; (iii) the thermal conductivity should be taken into account to avoid the thermal degradation of OLEDs during the continuous usage; (iv) the transparent barriers need to be fabricated with low-temperature process to promote the performance of OLEDs, and the cleanliness of the chambers should be guaranteed to avoid the particle contamination, which may damage the barriers; and (v) the higher deposition rate is necessary for the commercial applications with mass production.

Atomic layer deposition (ALD) is known to be a powerful ultrathin film fabrication method based on the time-sequenced self-limiting reactions, and the film thickness and uniformity can be controlled precisely even when applied to the large-area

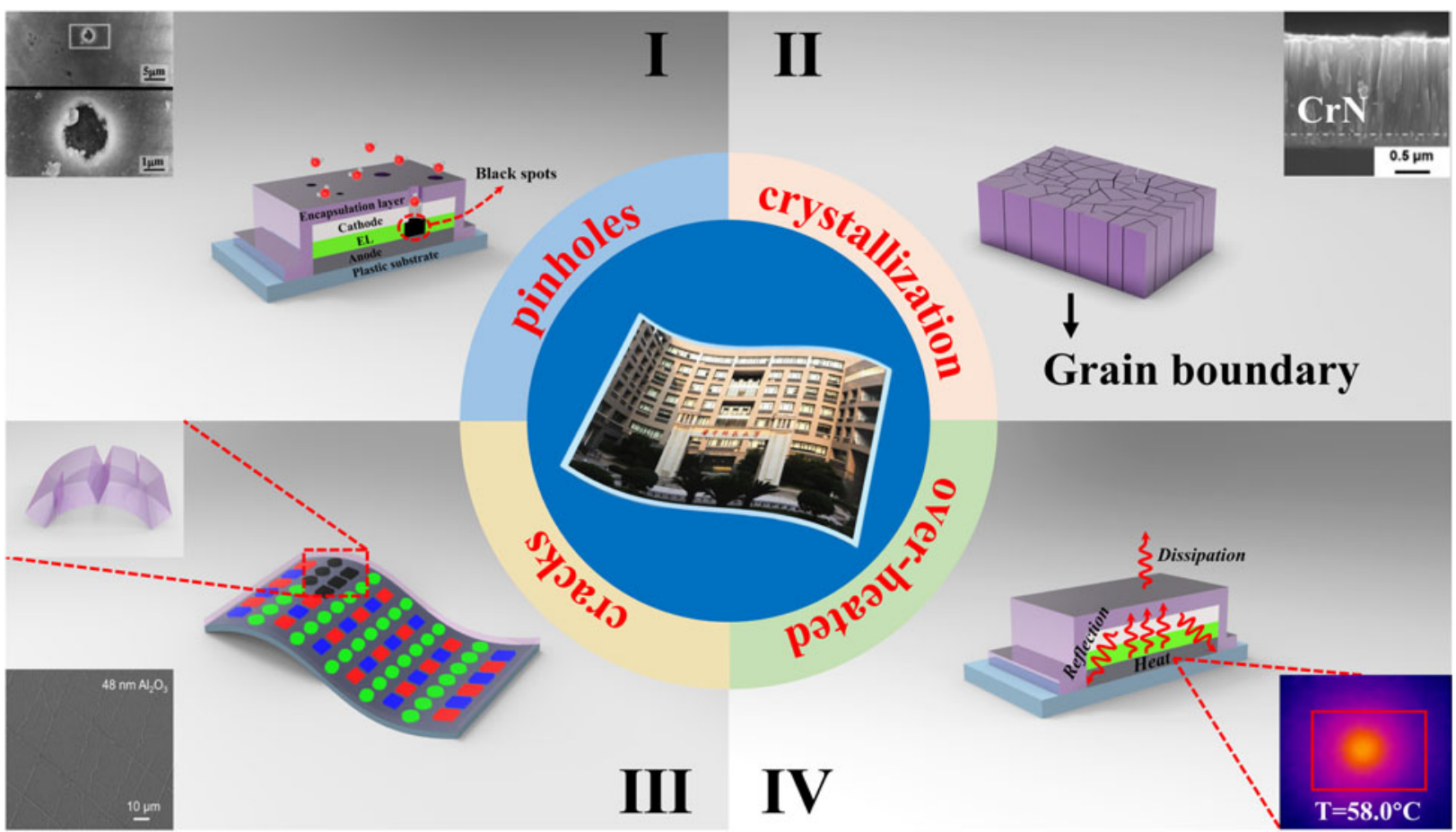

Figure 1: Different degeneration paths of the barrier structures: (a) black spots aroused by the pinholes, (b) grain boundaries as the permeation paths, (c) cracks of the barrier structures, and (d) over-heated caused by poor thermal conductivity. 
substrates [32]. The densely packed and pinhole-free ALDbased films can be deposited directly on the devices through low-temperature processes, and the conformal films can be utilized as high-quality barriers for organic devices [33, 34, 35]. In this review, different ALD-based approaches are introduced to solve the specific problems shown in Fig. 1, including the monolayer films, composite structures, and inorganic nanolaminates, which can inhibit the pinholes and crystallization, and the optical transmittance can be tuned to promote the performance of OLEDs. To eliminate the cracking through the stress, the polymers or oxides with reversal residual stress are combined to improve the barrier flexibility. Meanwhile, the location of the neutral axis (NA) can be optimized to reduce the strain applied to the fragile layers. Furthermore, the materials with high thermal conductivity are inserted to transport the heat out of the devices, which can protect the emitting layer from thermal aging. Besides, the ALD reactors and processes for TFE are also reviewed. Finally, the future development of the ALD methods for the TFE of OLEDs is also discussed.

\section{Monolayer and composite structures}

To suppress the black spots aroused by the pinholes of the barrier layers, different materials and deposition methods, including thermal evaporation, CVD, and sputtering, have been utilized to obtain the densely packed encapsulation structures, and the preparation processes and structures have been optimized by the experimental or simulation methods.

Similar to the glass lid, the constricted interstitial spaces of the Si-O lattice can block the moisture diffusion effectively [36], but the high-temperature process of $\mathrm{SiO}_{x}$ via CVD limits its application in OLEDs [37, 38, 39]. George and colleagues reported that the $\mathrm{SiN}_{x}$ layer could be fabricated at low temperature via PE-CVD, but it has poor barrier property, and it was speculated that the lower density columnar boundaries in $\mathrm{SiN}_{x}$ layer may present pathways for moisture $[40,41,42]$. Similar result was found in $\mathrm{SiO}_{x}$ films prepared via thermal evaporation [43]. Thus, great attention has been paid to the ALD method due to its unique assets. Among the various dielectrics prepared via ALD method, $\mathrm{Al}_{2} \mathrm{O}_{3}$ is the most studied material due to the superior barrier property. In the deposition processes of trimethylaluminum (TMA) and $\mathrm{H}_{2} \mathrm{O}$ (deionized water), the excessive precursors and by-products methane are hard to be removed out of the ALD chamber due to the low deposition temperature, resulting in incomplete chain reaction and increasing voids $[32,44]$. Duan and colleagues utilized the computational fluid dynamics to calculate the amount of species absorbed on the substrate surfaces [45, 46, 47], and a longer purge time was adopted to remove the excessive precursors and by-products (Table I, line 10). With the optimized process parameters, the water vapor transmittance rate (WVTR) of 70-nm-thick $\mathrm{Al}_{2} \mathrm{O}_{3}$ obtained at $80{ }^{\circ} \mathrm{C}$ improved to $10^{-2} \mathrm{~g} / \mathrm{m}^{2} \cdot$ day, and similar result was also reported by Carcia and colleagues [48]. To increase the density to lower down the WVTR of $\mathrm{Al}_{2} \mathrm{O}_{3}$ films further, Yang et al. replaced the $\mathrm{H}_{2} \mathrm{O}$ with $\mathrm{O}_{3}$ as the oxidant with a shorten purge time due to the lower viscosity of $\mathrm{O}_{3}$ than $\mathrm{H}_{2} \mathrm{O}$ [49], resulting in a higher deposition efficiency (Table $\mathrm{I}$, line 11). Besides, the $\mathrm{O}_{3}$ with higher reactivity can consume the TMA more sufficiently [50, 51]. An improved hydrophobic property of the $\mathrm{O}_{3}$-based $\mathrm{Al}_{2} \mathrm{O}_{3}$ films was revealed via the water contact analysis, and the barrier property was two orders of magnitude higher than that of $\mathrm{H}_{2} \mathrm{O}$-based $\mathrm{Al}_{2} \mathrm{O}_{3}$ film. Duan and colleagues revealed that the transient steric hindrance in low-temperature deposition process caused by the by-product gas molecules would block part of the active sites on the substrates, which prevented the reactions with the precursors [52]. Therefore, the $\mathrm{H}_{2} \mathrm{O}$-based $\mathrm{Al}_{2} \mathrm{O}_{3}$ films contained a large number of unreacted $-\mathrm{CH}_{3}$ groups and $\mathrm{O}_{3}$-based films left more carbon-based impurities [53]. Hence, the multiple short pulse process was adopted to reduce the transient steric hindrance. In this way, the oxidant precursor will be injected into the chamber twice in one cycle, which is separated with a purge process, and the active sites can be consumed completely. Similarly, Peng and colleagues

TABLE I: Summary of the WVTR values of monolayer.

\begin{tabular}{|c|c|c|c|c|c|c|}
\hline $\begin{array}{l}\text { Line } \\
\text { No. }\end{array}$ & $\begin{array}{c}\text { Material } \\
\text { (methods) }\end{array}$ & Precursor & $\begin{array}{c}\text { Thickness } \\
(\mathrm{nm})\end{array}$ & $\begin{array}{l}\text { Test temp. } \\
\left({ }^{\circ} \mathrm{C}\right) / \mathrm{RH}(\%)\end{array}$ & $\begin{array}{c}\text { WVTR } \\
\left(\mathrm{g} / \mathrm{m}^{2} \cdot \text { day }\right)\end{array}$ & Ref. \\
\hline 1 & $\begin{array}{c}\mathrm{SiO}_{2} \\
(\mathrm{PE}-\mathrm{CVD})\end{array}$ & $\begin{array}{c}\text { HDMSO, } \mathrm{O}_{2} \\
\mathrm{Ar}_{2}\end{array}$ & $>100$ & $23 / 50$ & $2.0 \times 10^{-1}$ & [48] \\
\hline 2 & $\mathrm{SiN}_{x}$ & $\mathrm{SiH}_{4}, \mathrm{~N}_{2}$ & 50 & $60 / 85$ & $2.0 \times 10^{-2}$ & [42] \\
\hline 3 & (PE-CVD) & $\mathrm{SiH}_{4}, \mathrm{~N}_{2}, \mathrm{NH}_{4}$ & 300 & $25 / 50$ & $4.0 \times 10^{-6}$ & [18] \\
\hline 4 & & & 26 & $23 / 50$ & $1.1 \times 10^{-3}$ & [48] \\
\hline 5 & & & 73 & $25 / 80$ & $2.1 \times 10^{-4}$ & [49] \\
\hline 6 & & & 60 & $20 / 60$ & $4.9 \times 10^{-4}$ & [50] \\
\hline 7 & & TMA $+\mathrm{H}_{2} \mathrm{O}$ & 100 & $60 / 60$ & $8.0 \times 10^{-5}$ & [55] \\
\hline 8 & & & 50 & $25 / 50$ & $4.0 \times 10^{-6}$ & [56] \\
\hline 9 & $\mathrm{Al}_{2} \mathrm{O}_{3}$ & & 50 & $38 / 100$ & $1.0 \times 10^{-1}$ & [62] \\
\hline 10 & (ALD) & & 100 & $25 / 80$ & $4.0 \times 10^{-3}$ & [45] \\
\hline 11 & & & 81 & $25 / 80$ & $8.7 \times 10^{-6}$ & [49] \\
\hline 12 & & $\mathrm{IMA}+\mathrm{O}_{3}$ & 60 & $20 / 60$ & $8.7 \times 10^{-6}$ & [50] \\
\hline 13 & & & 50 & $25 / 50$ & $4.0 \times 10^{-6}$ & [56] \\
\hline 14 & & $\begin{array}{c}\mathrm{TMA}+\mathrm{H}_{2} \mathrm{O} \\
+\mathrm{O}_{3}\end{array}$ & 47 & $40 / 100$ & $\begin{array}{c}5.43 \times \\
10^{-5}\end{array}$ & [44] \\
\hline 15 & & & 100 & $60 / 60$ & $5.0 \times 10^{-5}$ & [55] \\
\hline 16 & $\mathrm{H}_{2} \mathrm{U}_{3}$ & IIVA $+U_{2}$ & 50 & $25 / 50$ & $6.0 \times 10^{-5}$ & [56] \\
\hline 17 & & & 50 & $60 / 90$ & $3.8 \times 10^{-4}$ & [59] \\
\hline 18 & & $\begin{array}{c}\text { TDMAZr }+ \\
\mathrm{H}_{2} \mathrm{O}\end{array}$ & 80 & $20 / 60$ & $\begin{array}{c}3.74 \times \\
10^{-3}\end{array}$ & [51] \\
\hline 19 & $\mathrm{ZrO}_{2}$ & $\begin{array}{c}\text { TDMAZr + } \\
\mathrm{O}_{3}\end{array}$ & 80 & $20 / 60$ & $\begin{array}{c}6.09 \times \\
10^{-4}\end{array}$ & [51] \\
\hline 20 & & $\begin{array}{c}\text { TEMAZr }+ \\
\mathrm{O}_{3}\end{array}$ & 100 & $50 / 50$ & $\begin{array}{c}3.87 \times \\
10^{-3}\end{array}$ & [58] \\
\hline 21 & $\mathrm{TiO}_{2}$ & $\begin{array}{c}\text { TDMAT }+\mathrm{O}_{2} \\
\text { plasma }\end{array}$ & 50 & $60 / 90$ & $\begin{array}{c}6.32 \times \\
10^{-4}\end{array}$ & [59] \\
\hline 22 & $\mathrm{MgO}$ & $\begin{array}{c}\mathrm{Mg}(\mathrm{CpEt})_{2}+ \\
\mathrm{H}_{2} \mathrm{O}\end{array}$ & 60 & $30 / 90$ & $\begin{array}{c}5.83 \times \\
10^{-2}\end{array}$ & [61] \\
\hline
\end{tabular}


reported that the $\mathrm{Al}_{2} \mathrm{O}_{3}$ films prepared by the $\mathrm{H}_{2} \mathrm{O}$ and $\mathrm{O}_{3}$ in turn in one cycle as oxidants performed higher density and purity, leading to the superior barrier property [44] (Table I, line 14). Besides, Hoffmann et al. utilized the plasma-enhanced atomic layer deposition (PE-ALD) to improve the film quality $[54,55,56]$, and the $\mathrm{Al}_{2} \mathrm{O}_{3}$ films showed an ultralow WVTR value of $10^{-6} \mathrm{~g} / \mathrm{m}^{2}$.day (Table I, line 13).

The investigations of the monolayers such as $\mathrm{ZnO}_{2}$ and $\mathrm{ZrO}_{2}$ have also been carried out. Choi and colleagues prepared pure $\mathrm{ZnO}$ and doped $\mathrm{ZnO}$ films, and the real-time resistance changes of them at $85{ }^{\circ} \mathrm{C} / 85 \%$ relative humidity (RH) were monitored [57]. The measurement results indicated that the doped $\mathrm{ZnO}$ film had more corrosion resistance than the pure $\mathrm{ZnO}$ layer. It revealed that the degradation of the electrical conductivity of pure $\mathrm{ZnO}$ layer was due to the higher potential energy barrier when the $-\mathrm{OH}$ groups chemisorbed along the grain boundary, which agreed well with the transmission electron microscope (TEM) result. However, in the doped $\mathrm{ZnO}$ film, the $\mathrm{Al}$ and $\mathrm{Mg}$ dopants could substitute the $\mathrm{Zn}$ and hinder the crystallization. Oh et al. prepared the $\mathrm{Al}_{2} \mathrm{O}_{3}$ and $\mathrm{ZrO}_{2}$ monolayers with the same thickness of $100 \mathrm{~nm}$, which corresponded to the WVTRs of $7.05 \times 10^{-4}$ and $3.87 \times 10^{-3} \mathrm{~g} / \mathrm{m}^{2} \cdot$ day [58], respectively (Table I, line 20). The high-resolution transmission electron microscope (HR-TEM) was utilized to obtain the structural information about the $\mathrm{ZrO}_{2}$ film, the growth of which followed the [111] direction, and the grain boundaries acted as the permeation path. Similar results have been reported in the monolayers of $\mathrm{TiO}_{2}$ [59], $\mathrm{MgO}[60,61]$, etc. The processes and barrier properties of the monolayer structure via ALD are summarized in Table I.

The performance of the OLEDs encapsulated with monolayer and composite structures has been investigated. Kessels and colleagues counted the growth behavior of the black spots on the OLEDs encapsulated with different structures at $20{ }^{\circ} \mathrm{C} / 50 \% \mathrm{RH}$. As shown in Fig. 2(a), the $\mathrm{Al}_{2} \mathrm{O}_{3}$ layer has better barrier property than the $\mathrm{SiN}_{x}$ layer [16]. Besides, the black spot density of $\operatorname{SiN}_{x}$ was much higher than that of others after long time storage, as shown in Fig. 2(b), and a higher average growth rate of black spots was found in the $\mathrm{Al}_{2} \mathrm{O}_{3}$ layer due to uncovered large defects. In addition, the barrier resistance of the composite $\mathrm{Al}_{2} \mathrm{O}_{3} / \mathrm{SiN}_{x}$ structure improved significantly compared with the monolayers $[62,63]$. The pinholes and low-density columnar boundaries could be sealed up effectively via ALD method [42]. Maindron et al. investigated the occurrence and growth mechanism of the black spots of nonfluorescent tris-(8hydroxyquinoline) aluminum $\left(\mathrm{AlQ}_{3}\right)$ in the accelerated conditions [43]. It was found that the barrier structures containing $\mathrm{Al}_{2} \mathrm{O}_{3}$ layer presented a lag time $\tau$ due to the pinhole-free property of the ALD-based $\mathrm{Al}_{2} \mathrm{O}_{3}$ films, after which the defect densities started to increase significantly. The observation results of $\mathrm{SiO}_{x}$ and $\mathrm{Al}_{2} \mathrm{O}_{3}$ are shown in Figs. 2(c) and 2(d). The black spot occurrence rates were decomposed into different regimes (numbered 1, 2, and 3), and the hatched area in Fig. 2(d) represents the total fluorescence failure of the device, where the inset means the enlarged data plots in $0-200 \mathrm{~h}$ time range. Park and colleagues revealed that the harsh environment (high temperature and humidity) made the encapsulation layers deteriorating to the porous "flowerlike" structure [59]. After the lag time, the growth rate of the black spot number increased rapidly due to the corrosion of $\mathrm{Al}_{2} \mathrm{O}_{3}$ [64], leading to a higher growth rate of defect density for $\mathrm{Al}_{2} \mathrm{O}_{3}$ film than that of $\mathrm{SiO}_{x}$ film in regime 2. When coating the $\mathrm{Al}_{2} \mathrm{O}_{3}$ film with $\mathrm{SiO}_{x}$, the longest lag time and slowest growth rate of the defect density were obtained compared with those of other structures.

\section{Inorganic nanolaminates}

As mentioned above, the oxide films such as $\mathrm{ZnO}[65,66]$, $\mathrm{TiO}_{2}$ [67], and $\mathrm{ZrO}_{2}[51,68]$ tend to crystallize with the increasing thickness, and the grain boundaries would serve as the pathway for the moisture to permeate into the devices, resulting in the degradation of the OLED displays. To further decrease the thickness and suppress the crystallization of the barrier structures, great attention has been paid to the laminated structures

Based on the activated rate theory, a simple empirical model for the change in permeation mechanism of laminated structures is deduced as below [36], where $P_{\text {com }}$ denotes the permeation rate of the overall structure and $P_{1}, P_{2}$, etc., mean the permeation rates of sublayer $1,2 \ldots$ respectively.

$$
P_{\text {com }}=\left[1 / P_{1}+1 / P_{2}+1 / P_{3}+\cdots\right]^{-1} \text {. }
$$

This ideal series assumes that each component is continuous, and the interfaces between each component are not lowenergy conduits to transport. However, the theory is not consistent with the entire experimental results due to the imperfection of the sublayers, and the permeation mechanism in the laminated structures needs to be clarified with in-depth researches.

Prior to the activated rate theory [36], the barrier property of the encapsulation structure improves with the increase in the sublayer numbers. However, the thicker the inorganic barriers are, the less flexible they are. Besides, the repeated transfer process in different vacuum chambers leads to particle contamination [69], resulting in the destruction of the barriers. Attentions have been focused on the nanolaminates prepared via ALD method, which can be obtained in one chamber continuously [70, 71]. As shown in Fig. 3(a), we reported that the optical property of $\mathrm{ZnO} / \mathrm{TiO}_{2}$ nanolaminates (such as 

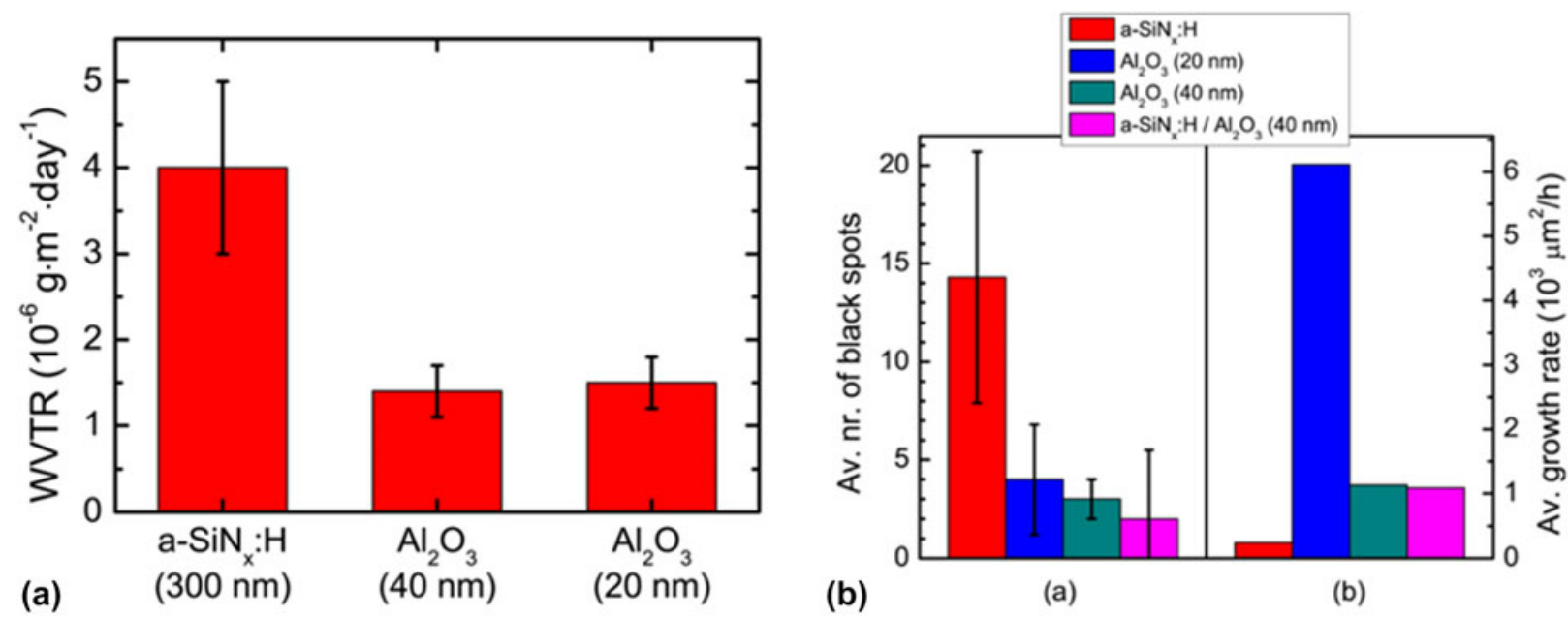

(b)

(a)

(b)
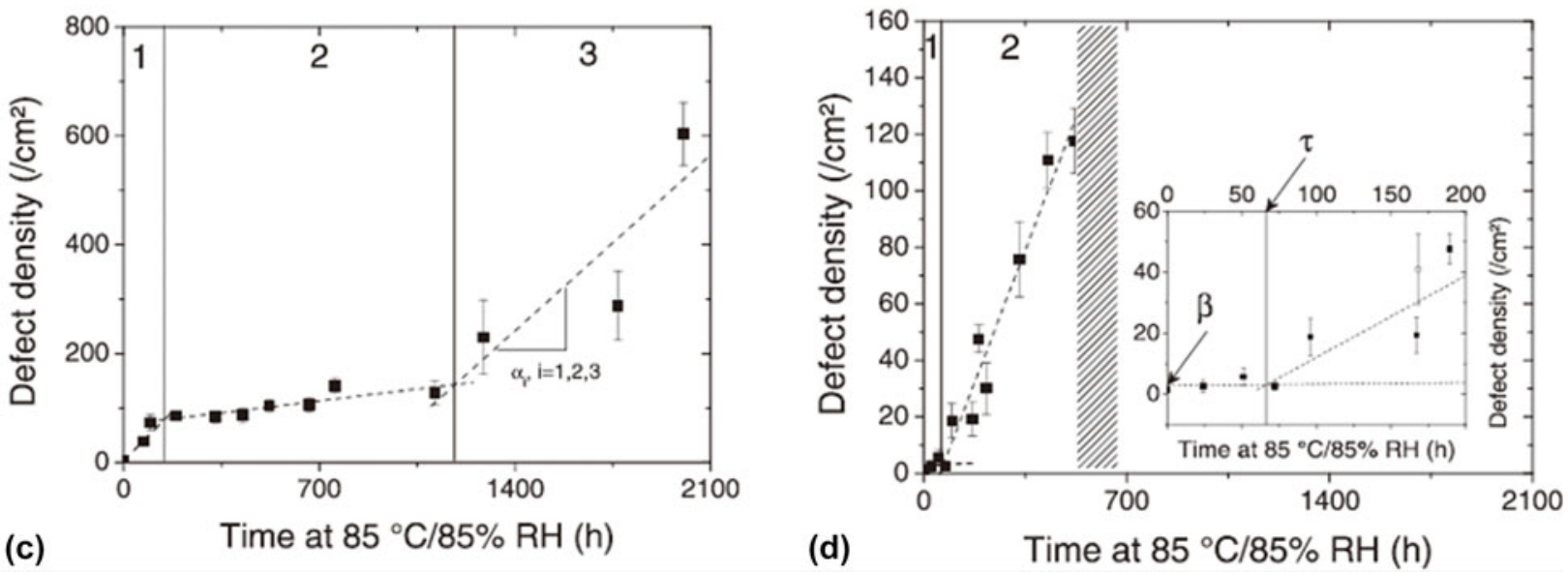

Figure 2: (a) Intrinsic WVTR values measured for a-SiN $\mathrm{N}_{x}: \mathrm{H}$ (PE-CVD) and $\mathrm{Al}_{2} \mathrm{O}_{3}$ (PE-ALD) films; (b) average number and the average growth rates of black spots on OLED samples encapsulated with different structures; and defect density evolution versus storage time for device encapsulated with (c) evaporated $\mathrm{SiO}_{2}$ layer and (d) $\mathrm{Al}_{2} \mathrm{O}_{3}$ layer.

refractive index and transparency) could be tuned by adjusting the number of sublayers with the thickness of overall structure maintained constant [72]. Besides, the increasing number and decreasing thickness of sublayers lead to the amorphous structure of the barriers according to the XRD patterns shown in Fig. 3(b). Similar results were reported by George and colleagues, and the electrical and mechanical properties could also be adjusted [73, 74]. Meyer et al. reported the $\mathrm{Al}_{2} \mathrm{O}_{3} / \mathrm{ZrO}_{2}$ nanolaminates as ultrahigh gasdiffusion barriers; the barrier performance of which improved 1-2 orders of magnitude compared with that of the $\mathrm{Al}_{2} \mathrm{O}_{3}$ layer in the accelerated condition of $70{ }^{\circ} \mathrm{C} / 70 \% \mathrm{RH}$ [75] (Table II, line 2). The low-temperature deposition process led to the incomplete precursor reaction, which agreed well with the Fourier transform infrared spectroscopy (FTIR) results [76]. The amorphous $\mathrm{Al}_{2} \mathrm{O}_{3}$ hindered the crystallization of $\mathrm{ZrO}_{2}$ in the $\mathrm{Al}_{2} \mathrm{O}_{3} / \mathrm{ZrO}_{2}$ nanolaminates. Besides, the $\mathrm{ZrO}_{2}$ layer could prevent the accumulation of unreacted $\mathrm{Al}-\mathrm{OH}$ species and the formation of extended voids in the $\mathrm{Al}_{2} \mathrm{O}_{3}$ sublayers, increasing the packing density. Besides, Jeon and colleagues demonstrated the formation of $\mathrm{ZrAl}_{x} \mathrm{O}_{y}$-aluminate phase at the interfaces via the $\mathrm{X}$-ray photoelectron microscopy characterization $[77,78]$ (Table II, lines 3 and 5), which is shown in Figs. 3(c) and 3(d). The Al $2 p$ core level was shifted toward a lower binding energy, and the $\mathrm{Zr} 3 d$ core level was shifted toward a higher binding energy. Taking the electronegativity of $\mathrm{Al}$ (1.61) and $\mathrm{Zr}$ (1.33) into consideration, $\mathrm{Zr}$ tend to donate an electron and $\mathrm{Al}$ tend to gain an electron to form a strong chemical bonding. Juhong et al. even obtained the pure $\mathrm{ZrAl}_{x} \mathrm{O}_{y}$ phase structure by conducting $\mathrm{Al}$ cycle and $\mathrm{Zr}$ cycle alternatively, which performed the best barrier property [58] (Table II, line 4).

Similar to the $\mathrm{Al}_{2} \mathrm{O}_{3} / \mathrm{ZrO}_{2}$ system, Lae et al. prepared the $\mathrm{Al}_{2} \mathrm{O}_{3} / \mathrm{TiO}_{2}$ nanolaminates by conducting the $\mathrm{Al}$ cycle and $\mathrm{Ti}$ cycle alternatively [59] (Table II, line 1). The $\mathrm{Al}_{2} \mathrm{O}_{3}$ monolayer and $\mathrm{Al}_{2} \mathrm{O}_{3} / \mathrm{TiO}_{2}$ nanolaminates were immersed in water at 

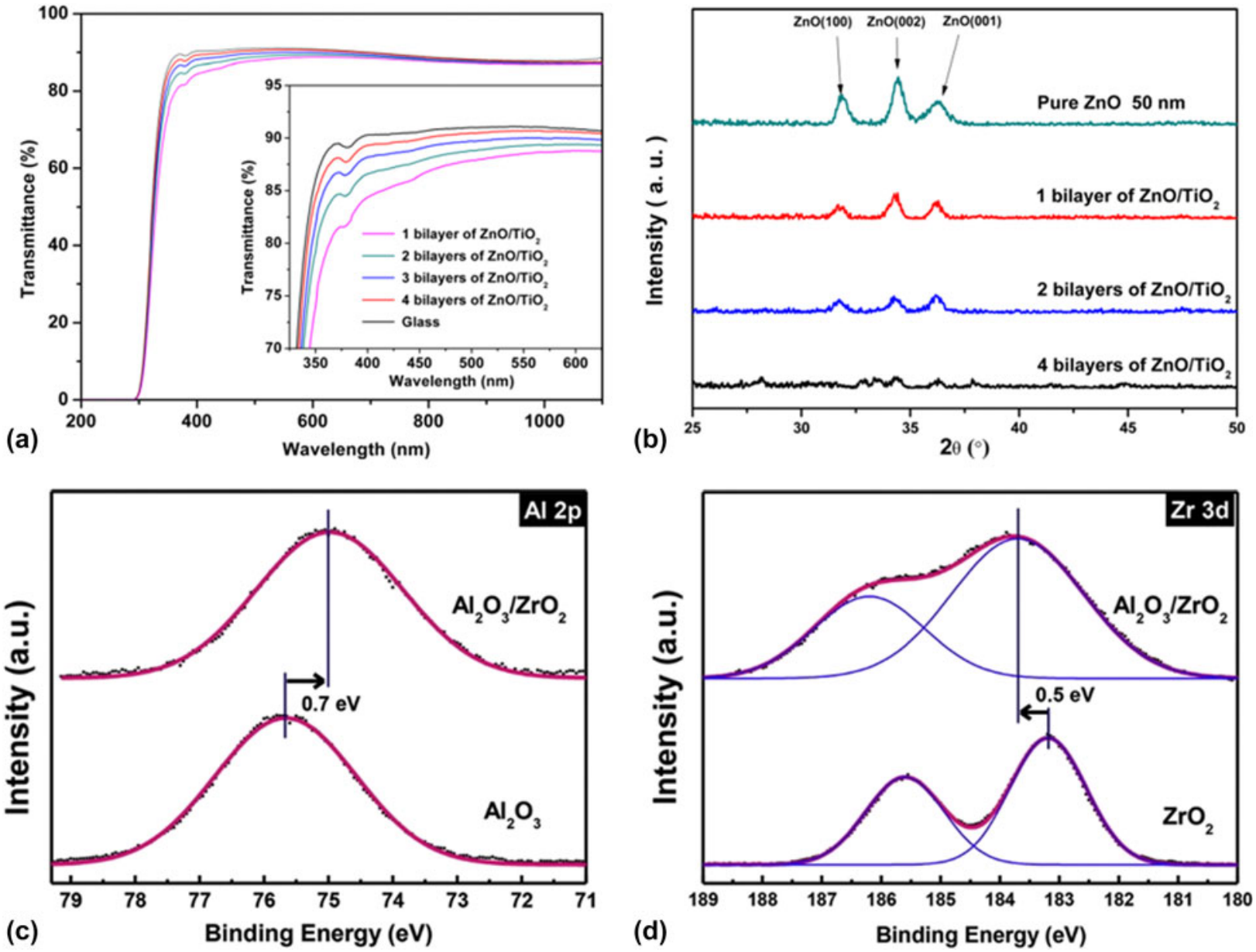

Figure 3: (a) Transmittance of $\mathrm{ZnO} / \mathrm{TiO}_{2}$ laminates at different bilayers' number on glass substrate; (b) grazing incidence $\mathrm{X}$-ray diffraction of the asdeposited $\mathrm{ZnO} / \mathrm{TiO}_{2}$ laminates; $\mathrm{X}$-ray photoelectron spectroscopy (XPS) spectra of $\mathrm{Al}_{2} \mathrm{O}_{3}, \mathrm{ZrO}_{2}$, and $\mathrm{ZrAl}_{x} \mathrm{O}_{y}$ phase of (c) $\mathrm{Al} 2 p$ and (d) $\mathrm{Zr} 3 d$ core levels.

TABLE II: Summary of the barrier properties of nanolaminates.

\begin{tabular}{|c|c|c|c|c|c|c|}
\hline $\begin{array}{l}\text { Line } \\
\text { No. }\end{array}$ & $\begin{array}{l}\text { Material } \\
\text { (method) }\end{array}$ & Precursors & $\begin{array}{c}\text { Thickness } \\
\text { (nm) (\# of } \\
\text { dyads) }\end{array}$ & $\begin{array}{c}\text { Test Temp. } \\
\left({ }^{\circ} \mathrm{C}\right) / \mathrm{RH} \\
(\%)\end{array}$ & $\begin{array}{c}\text { WVTR } \\
\left(\mathrm{g} / \mathrm{m}^{2} \cdot \text { day }\right)\end{array}$ & Ref. \\
\hline 1 & $\begin{array}{c}\mathrm{Al}_{2} \mathrm{O}_{3} / \\
\mathrm{TiO}_{2}(\mathrm{PE}- \\
\text { ALD) }\end{array}$ & $\begin{array}{c}\text { TMA, } \\
\text { TDMAT, } \mathrm{O}_{2} \\
\text { plasma }\end{array}$ & $\begin{array}{l}50 \text { (cyclic } \\
\text { ratio: } 1: 1 \text { ) }\end{array}$ & $60 / 90$ & $\begin{array}{c}1.81 \times \\
10^{-4}\end{array}$ & [59] \\
\hline 2 & & TMA, & $2.6 / 3.6(20)$ & $70 / 70$ & $\begin{array}{r}4.7 \times \\
10^{-5}\end{array}$ & $\begin{array}{l}{[75,} \\
76]\end{array}$ \\
\hline 3 & $\begin{array}{l}\mathrm{Al}_{2} \mathrm{O}_{3} / \\
\mathrm{ZrO}_{2}\end{array}$ & $\begin{array}{c}\text { TDMAZr, } \\
\mathrm{H}_{2} \mathrm{O}\end{array}$ & $2.1 / 3.1(20)$ & $80 / 80$ & $\begin{array}{r}3.2 \times \\
10^{-4}\end{array}$ & [78] \\
\hline 4 & (ALD) & $\begin{array}{c}\text { TMA, } \\
\text { TEMAZr, } \mathrm{O}_{3}\end{array}$ & $\begin{array}{l}100 \text { (cyclic } \\
\text { ratio: } 1: 1 \text { ) }\end{array}$ & $50 / 50$ & $\begin{array}{c}3.26 \times \\
10^{-4}\end{array}$ & [58] \\
\hline 5 & $\begin{array}{c}\mathrm{Al}_{2} \mathrm{O}_{3} / \\
\mathrm{ZrO}_{2}(\mathrm{PE}- \\
\mathrm{ALD})\end{array}$ & $\begin{array}{c}\text { TMA, } \\
\text { TEMAZr, } \mathrm{O}_{2} \\
\text { plasma }\end{array}$ & $\begin{array}{l}100 \text { (cyclic } \\
\text { ratio: } 1: 1 \text { ) }\end{array}$ & $50 / 50$ & $\begin{array}{r}9.9 \times \\
10^{-4}\end{array}$ & [77] \\
\hline
\end{tabular}

$90{ }^{\circ} \mathrm{C}$ for $30 \mathrm{~min}$, and the topography of the samples was characterized by atomic force microscopy (AFM) and fieldemitting scanning electron microscopy (FE-SEM). As shown in Fig. 4, the surface roughness increased significantly and petal structures were formed for the individual $\mathrm{Al}_{2} \mathrm{O}_{3}$ layer. In contrast, the surface of the nanolaminates remained smooth, which demonstrated the excellent water-corrosion-resistant property of the $\mathrm{TiAl}_{x} \mathrm{O}_{y}$-aluminate phase. Similar results could be found for $\mathrm{Al}_{2} \mathrm{O}_{3} / \mathrm{SiO}_{2}$ [79, 80], $\mathrm{ZnO} / \mathrm{HfO}$ [22] nanolaminates, and the barrier properties of different nanolaminate encapsulation structures are listed in Table II.

\section{Hybrid structured TFEs under mechanical stresses}

The inorganic barrier structures carry intrinsic mechanical residual stress, and the stress increases with the increasing thickness of the overall structures [81]. Besides, when combined with the external stress caused by bending or stored in the harsh environment, the barrier layer tends to crack or delaminate from the device surface, leading to the degradation of the OLEDs. To make the barrier structures more flexible and to maintain the excellent barrier property, the hybrid laminated 

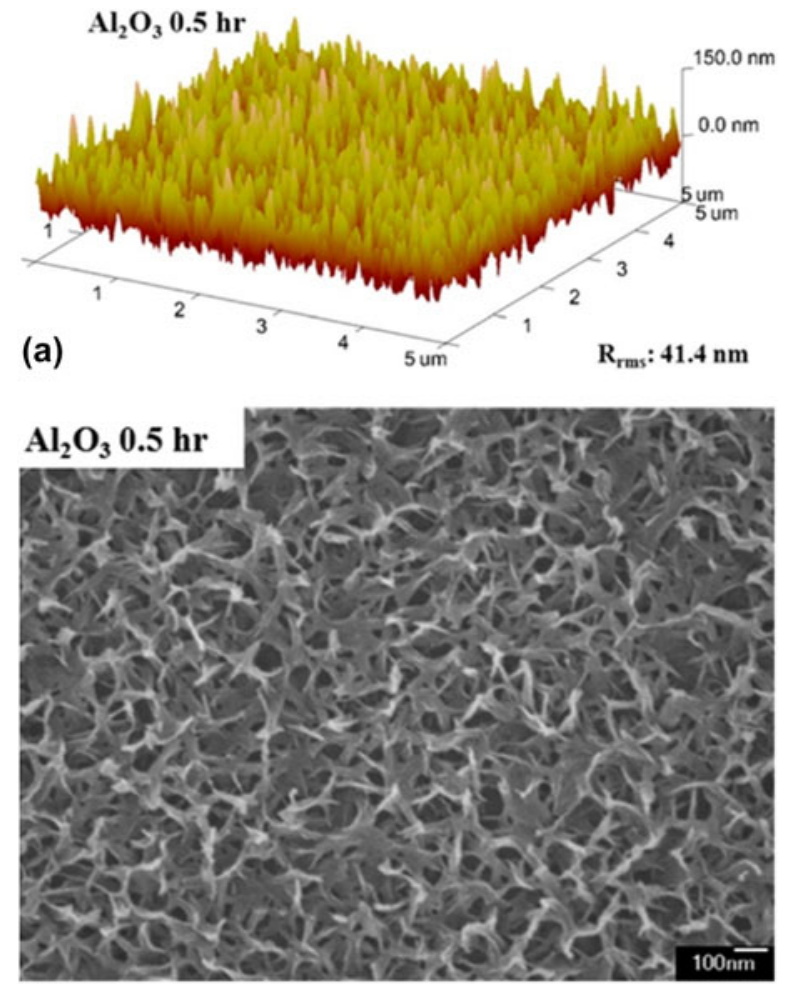

(c)
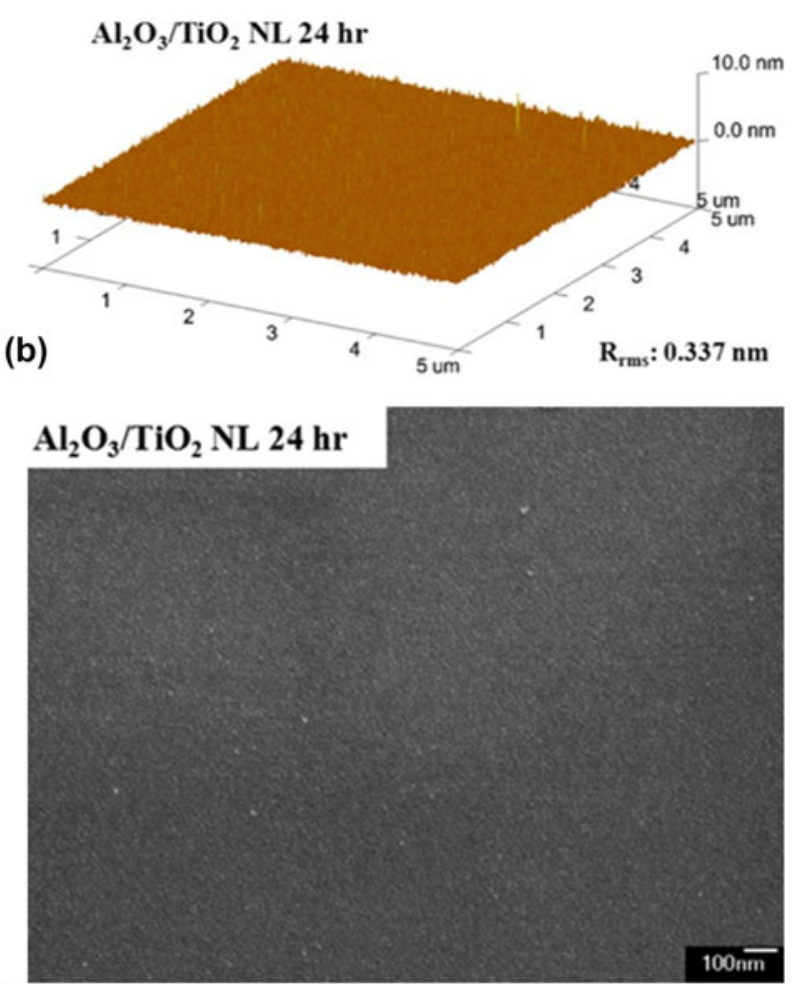

(d)

Figure 4: AFM images of the surfaces of the (a) single $\mathrm{Al}_{2} \mathrm{O}_{3}$ and $(\mathrm{b}) \mathrm{Al}_{2} \mathrm{O}_{3} / \mathrm{TiO}_{2}$ nanolaminate films after immersion in water at $90{ }^{\circ} \mathrm{C} ; \mathrm{FE}-\mathrm{SEM}$ photographs of the surfaces of (c) single $\mathrm{Al}_{2} \mathrm{O}_{3}$ and (d) $\mathrm{Al}_{2} \mathrm{O}_{3} / \mathrm{TiO}_{2}$ after immersion in water at $90{ }^{\circ} \mathrm{C}$.

structures with mechanical design and polymers embedded should be considered.

In particular, a wide range of ALD grown barrier layers carry tensile stress in the range of $400-500 \mathrm{Mpa}$ [81], and the cracking or delamination possibility increases significantly with the increasing thickness when stored in the extreme conditions (such as $85^{\circ} \mathrm{C} / 85 \% \mathrm{RH}$ ). As shown in Fig. 5(a), Bulusu et al. inserted an $\mathrm{SiN}_{x}$ layer with compressive stress to help release the stress of $\mathrm{Al}_{2} \mathrm{O}_{3} / \mathrm{HfO}_{2}$ nanolaminates, and the cracking probability of which decreased a lot [82]. An in-depth study was reported by Behrendt et al., in which a stress-thickness product $(\sigma \cdot h)$ was defined as the "membrane force" to evaluate the possibility of the cracking and delamination occurrence of barriers [83], and the threshold level was derived to be 1200 GPaÅ. The total membrane force $(\sigma \cdot h)_{\text {total }}$ of a multilayer can be derived by adding the contributions of the individual sublayers $(\sigma \cdot h)_{\mathrm{i}}$ :

$$
(\sigma \cdot h)_{\mathrm{total}}=\sum_{i} \sigma_{i} \cdot h_{i}
$$

It means that the membrane force of the multilayer does not depend on the sequence of the sublayers, which has been demonstrated by the experimental data. By introducing layers with compressive stress [such as $\mathrm{SiN}_{x}$ or Ag films, as shown in Fig. 5(b)] into the hybrid laminated structures [83], the membrane force can decrease to be below the threshold level.

The internal stress of the inorganic barrier structures can be released by combining the layers with reversal stress, but the barriers still tend to crack due to the bending fatigue when external stress is applied. The applied strain of the barriers under flexural deformation is proportional to the distance from the NA:

$$
\varepsilon=\left(\frac{Z-Z_{\mathrm{NA}}}{R}\right)
$$

where the $Z_{\mathrm{NA}}$ denotes the neutral position and $R$ means the bending radius. Besides, the thermal mismatch strain, humidity strain, etc., can be ignored when compared with the strain induced by bending. Thus, by shifting the neutral surface toward the barrier structure can reduce the external stress effectively. As for the simplified multilayer structure model, the NA position can be deduced as below:

$$
\sum_{i=0}^{n} \int_{Z_{i}-d_{i} / 2}^{Z_{i}+d_{i} / 2} E_{i} \varepsilon\left(Z-Z_{\mathrm{NA}}\right) w \mathrm{~d} Z=0
$$

where $Z_{i}, E_{i}, d_{i}$, and $w$ denote the location of the centroid, the elastic modulus, the thickness and cross-sectional width of the 
(a)

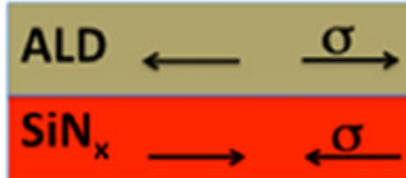

\section{Polymer}

\section{Glass}

\section{(a)}

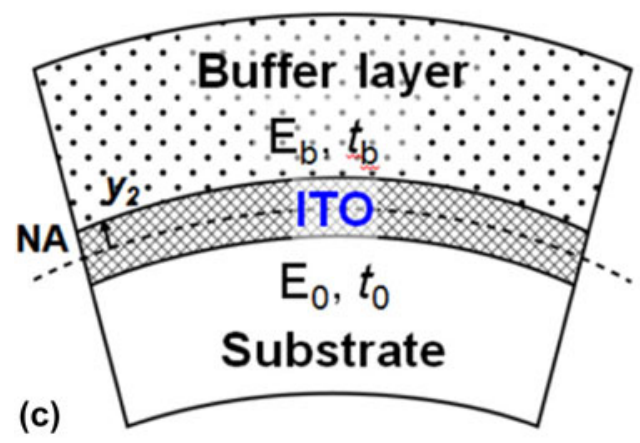

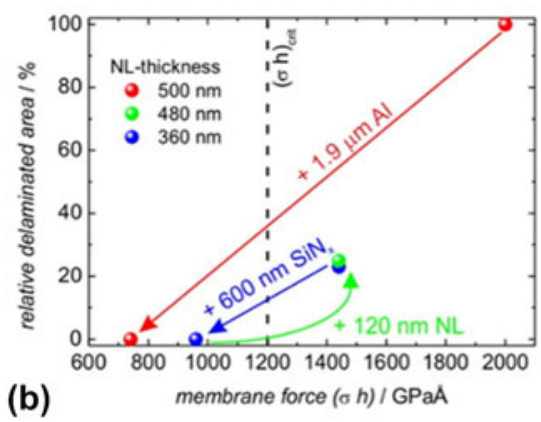

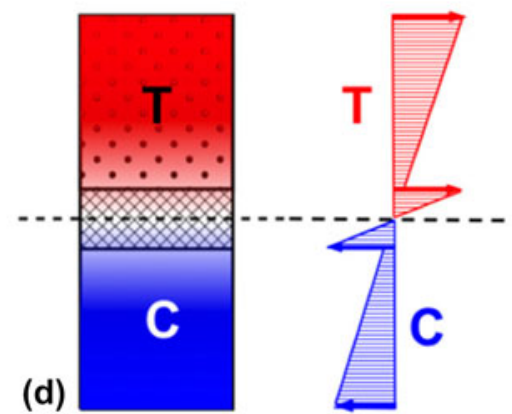

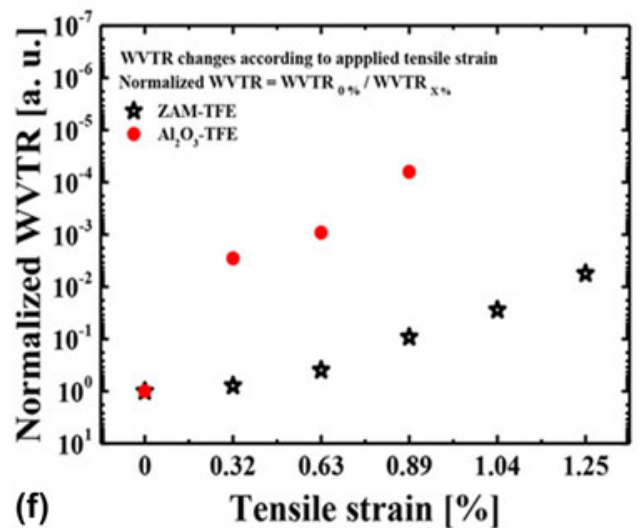

Figure 5: (a) Stress management via the insertion of $\mathrm{SiN}_{x}$ layer with compressive stress; (b) the relative delaminated area of $\mathrm{OLEDs}_{\mathrm{L}}$ comprising various $\mathrm{Al}_{2} \mathrm{O}_{3} / \mathrm{TiO}_{2}$ $\mathrm{NL} \mathrm{GDBs}$ with or without stress management layers $\left(\mathrm{SiN}_{x}\right.$ and $\mathrm{Ag}$ ); (c) NA positions of a flexible OLED, including ITO with a buffer layer; (d) stress distributions ( $E$ : elastic modulus, $t$ : thickness); (e) schematic of the nacre cross-section and bent ZAM film with energy dissipation system for crack deflection and crack arresting; and $(f)$ degradation of the barrier properties of $\mathrm{Al}_{2} \mathrm{O}_{3}$-TFE and ZAM-TFE with tensile strain applied.

$\mathrm{i}^{\text {th }}$ layer, respectively, and the $0^{\text {th }}$ material means the bottom device. As for the individual layers, the location of the centroid $\left(Z_{i}\right)$ of them will be utilized to simplify the calculation. Combing the Eqs. (3) and (4), the location of the NA position was deduced as below:

$$
Z_{\mathrm{NA}}=\frac{\sum_{i=0}^{n} Z_{i} E_{i} d_{i}}{\sum_{i=0}^{n} E_{i} d_{i}} .
$$

In the preparation of the flexible OLED devices, $d_{0} \gg d_{i}(i$ $\neq 0$ ), which revealed that the substrate thickness affects the applied strain on the barriers a lot. The theory was firstly applied in the design of the flexible OLEDs [as shown in Figs. 5(c) and 5(d)] [84]; Hwang et al. revealed that the stress of the ITO could be released significantly by adding a $250-\mu \mathrm{m}$ thick polyimide (PI) buffer layer, whose thickness is nearly equivalent to that of the PES substrate $(200 \mu \mathrm{m})$, and the strain decreased significantly when compared with that of OLED without buffer layer. Kim et al. added an epoxy top coating to shift the NA toward the encapsulation layer, and the barrier performance of the $\mathrm{SiO}_{2} / \mathrm{Al}_{2} \mathrm{O}_{3}$ laminates maintained unchanged under the $6.4 \mathrm{~mm}$ radius of curvature [85] (Table III, line 10). Similarly, Xu et al. added an organic protective layer [CYOTP, polydimethylsiloxane (PDMS), and $\mathrm{SU}-8]$ to the $\mathrm{Al}_{2} \mathrm{O}_{3} / \mathrm{MgO}$ laminates prepared by $\mathrm{ALD}$, in which 
the hydrophobic organic layer can protect the inorganic barrier from being corroded in the harsh environment and improve the flexibility [86] (Table III, lines 11-13). In addition, inspired by the microcrack toughening effect of the nacre structure, Jeong et al. reported the $\mathrm{ZnO} / \mathrm{Al}_{2} \mathrm{O}_{3} / \mathrm{MgO}$ (ZAM) laminated barrier structure for the flexible displays [60]. The ZAM film was formed with intentional voids and defects through the formation of a quasi-perfect sublayer, which is shown in Fig. 5(e). It was reported that the defect densities of ALD deposited films decreased linearly with thickness until reaching the critical thickness [87]. Based on that, the cycles were controlled for forming the first ultrathin films, maximizing the defect densities in sublayers before the formation of a perfect film with full coverage. The deposition process was optimized as cyclic ratio of 20/12/10 for the ZAM laminated structure, promoting the amorphous and layer-by-layer structure (Table III, line 15). The barrier property and mechanical stability of the ZAM/ organic hybrid structure under different strains improved significantly in comparison with an $\mathrm{Al}_{2} \mathrm{O}_{3}$ /organic multibarrier in the severe environment of $85^{\circ} \mathrm{C} / 90 \% \mathrm{RH}$ [88].

The particle generated during the fabrication of OLEDs or barrier structures also leads to the cracking, and it has been revealed that ALD is not effective for conformal coating on large particles and defects by Keuning et al. [18]. The polymers with flexibility and the very low elastic modulus and hardness are possible to address through the presence of particle contamination $[18,89]$. Therefore, the inorganic/organic laminated structures are considered [24], in which the barrier performance is dominated by the inorganic layers, and inorganic layers can be decoupled from the inorganic layer underneath by inserting the organic layers [90]. Meanwhile, the organic layers can release the internal stress of the encapsulation structures. Choi and colleagues investigated the $\mathrm{MgO} / \mathrm{S}-\mathrm{H}$ composite laminates [61] and revealed that the silicon particles embedded in the organic layers can extend the diffusion path effectively, resulting in the superior barrier performance equivalent to the glass lids (Table III, line 9). However, when immersed in water, the $\mathrm{S}-\mathrm{H}$ composite could not protect the inorganic layers from being corroded effectively [90]. Besides, Park and colleagues reported that the UV-cured procedure for S-H composite in the OLEDs [91, 92, 93] degraded the emitting layer. Thus, the introduction of thermally curable organic layers at low temperature is preferred in the fabrication of inorganic/organic alternating stacks, and the use of an ALD chamber with a vacuum below $10 \mathrm{~Pa}$ can lower the boiling point, enabling the organic layers to be cured at a relatively lower temperature. The silamer [94] and parylene C [95] were also utilized in the inorganic/ organic laminates, which showed a significant surface planarization effect. The water-corrosion-resistant polymers with randomly formed three-dimensional inner structures can protect the inorganic layers effectively due to the long tortuous diffusion path. Meanwhile, no significant increase in WVTR values was found after the bending tests due to the excellent mechanical stability of the inorganic/organic laminates.

TABLE III: Summary of the barrier properties of hybrid laminated structures.

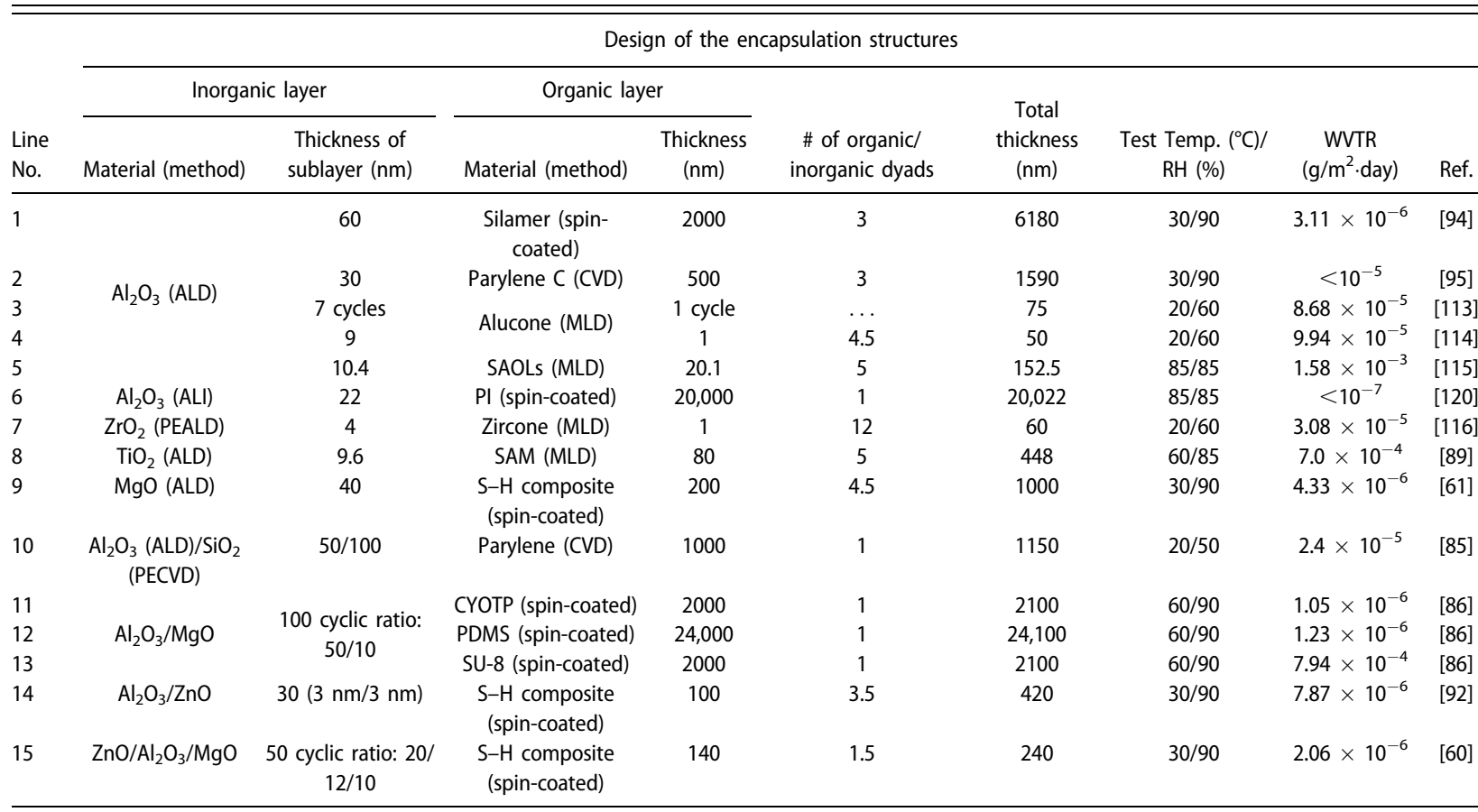


In the inorganic/organic laminated structures discussed above, pinholes are frequently found in the organic layers fabricated by the sol-gel methods [96]. Besides, the conformality and compositional uniformity at very small thickness are hard to guarantee [97]. The dry processes for depositing polymeric thin films have been proposed to overcome the problems aforementioned, such as CVD [98]. However, the free radicals utilized in CVD method may cause the loss of the precursors' functionalities [99], and the film properties like molecular orientation are hard to control. The method called molecular layer deposition (MLD) was proposed to fabricate the ultrathin organic films with precise thickness control, excellent uniformity, and conformity. The principle of MLD is similar to that of ALD, in which different precursors are injected into the chamber subsequently, which are separated with the purge processes, and it has been successfully applied to the fabrication of polyamide [100], polyimide [101], polyuria [102], etc. [103]. Besides, when replacing the inorganic oxidant reactants (like $\mathrm{H}_{2} \mathrm{O}$ and $\mathrm{O}_{3}$ ) with the organic ones (such as diols and carboxylic acids) in the ALD processes, the hybrid films with organic backbones and metal elements can be obtained. It has been reported to prepare alumina alkoxides (alucone) [104], zinc alkoxides (zincone) [105, 106], titanium alkoxides (titanicone) [107], etc., which possess lower hardness and elastic modulus than the corresponding oxides $\left(\mathrm{Al}_{2} \mathrm{O}_{3}\right.$, $\mathrm{ZrO}_{2}, \mathrm{TiO}_{2}$, etc.) [108]. However, the polymer-like hybrid films would uptake water in the ambient, leading to the erosion of the inner structure [104]. When covered with the inorganic layer, the degradation can be inhibited effectively [106]. As discussed elsewhere, due to the thermal expansion difference of the inorganic films and the plastic substrates, the films tend to crack with increasing thickness. Following Griffith's criterion, when the strain energy release rate $(G)$ from the surrounding strained material exceeds the interfacial toughness $\left(\Gamma_{i}\right)$, the crack will continue to propagate [109]. Here, the amount of stored elastic energy per unit area in a stressed thin film is:

$$
G=Z \frac{\sigma_{\mathrm{r}}^{2} h}{E}
$$

where $Z$ is a geometric constant, which ranges from 0.5 to 2.0 and $\sigma_{\mathrm{r}}$ and $h$ denote the residual stress and thickness of the deposited films, respectively. $E$ is the film's biaxial elastic modulus. With the increase in film thickness $h$, the residual stress increases gradually, especially when the high coefficient of thermal expansion (CTE) mismatch exists between the film and substrate. Both the increasing thickness and residual stress contribute to the increase in the stress release rate, and the crack can be observed due to the release of large amounts of energy. As shown in Figs. 6(a) and 6(b), George and colleagues reported that the insertion of the MLD interlayer could release the stress in the inorganic layers, and it was assumed that the "spring-like" organic interlayer with minimal cross-linking between the polymer chains could lower the compressive stress applied to the inorganic films [26], leading to the decrease in the crack probability $[110,111,112]$. Duan and colleagues demonstrated the improved barrier property of the alucone $/ \mathrm{Al}_{2} \mathrm{O}_{3}$ nanolaminates compared with that of $\mathrm{Al}_{2} \mathrm{O}_{3}$ single layer with the same thickness, which was due to the extended permeation path [113] (Table III, line 3), and the flexibility was also enhanced $[114,115,116]$.

Although the polymer substrates (such as PET and PEN) perform poor barrier property, their excellent flexibility attracts great interests from the researchers. Besides, the polymer films are easy to achieve high-throughput and low-cost fabrication with sol-gel methods. Nowadays, ALD method has been utilized to tune the mechanical and barrier properties of the polymer substrates widely $[117,118]$. To be exact, the growth behavior on the polymer substrates is strongly dependent on the chemical bonds (such as $-\mathrm{OH},-\mathrm{C}=\mathrm{O}-$, and $-\mathrm{NH}_{2}$ ) and process parameters (temperature, purge time, etc.) [119], which have been demonstrated by the quartz crystal microbalance and in situ FTIR investigations. The TMA molecules would diffuse into the sublayer and react with the groups on the surfaces, and the diffusion depth can be controlled to a certain extent by adjusting the process parameters. As shown in Fig. 6(c), Lee et al. reported a gas-proof polymer hybrid thin layer prepared via the atomic layer infiltration [120]. Compared with the ALD method, the precursors would not be purged out of the reaction chamber as soon as possible after the pulse, and the chamber was completely closed for a certain period for the precursors to diffuse into the polymers. After several tens of cycles, the voids in the substrates could be filled completely, which was confirmed by the energy-dispersive $\mathrm{X}$ ray spectroscopy, and the barrier property reached below $10^{-7}$ $\mathrm{g} / \mathrm{m}^{2}$. day while maintaining excellent flexibility (Table III, line 6), which is shown in Fig. 6(d). The barrier properties of the different hybrid laminated structures are listed in Table III.

\section{Thermal management layers}

Except for the degradation caused by the moisture erosion in the ambient, the flexible OLEDs based on the plastic substrates with low thermal conductivity face serious performance degradation if no additional heat sink system conducting the heat out of the device is contained [121]. Park et al. reported that the efficiency and lifetime were improved by inserting a metal sheet [122], but the rough surfaces and additional physical pressure would damage the OLED devices. Therefore, an ultrathin heat conducting film with excellent flexibility, ductility, and transparency is needed for the encapsulation for flexible OLEDs.

Among the various materials, graphene and silver possess the best heat conductivity, but the former one needs to be 
MLD/ALD at $135^{\circ} \mathrm{C}$

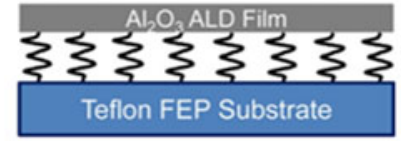

\section{Cool below $135^{\circ} \mathrm{C}$}

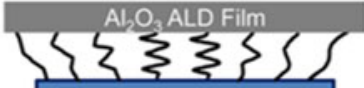

(a)
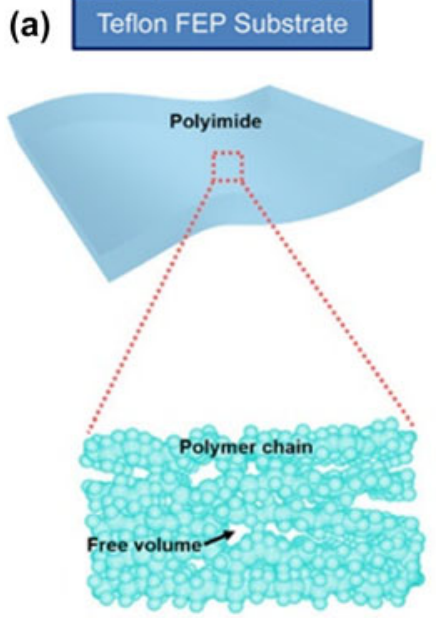

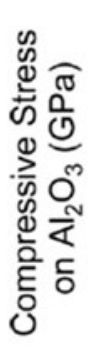

(b)

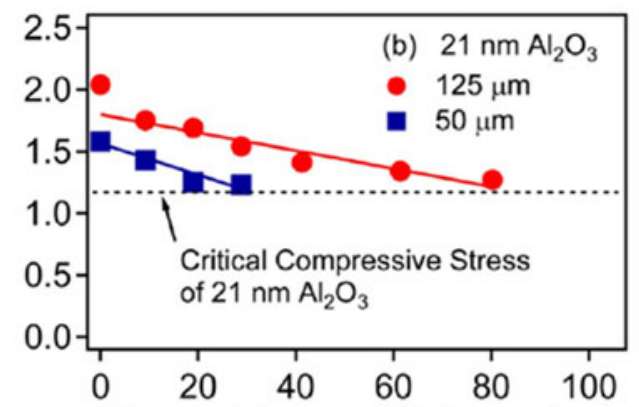

Alucone Interlayer Thickness ( $\mathrm{nm}$ )

(c)
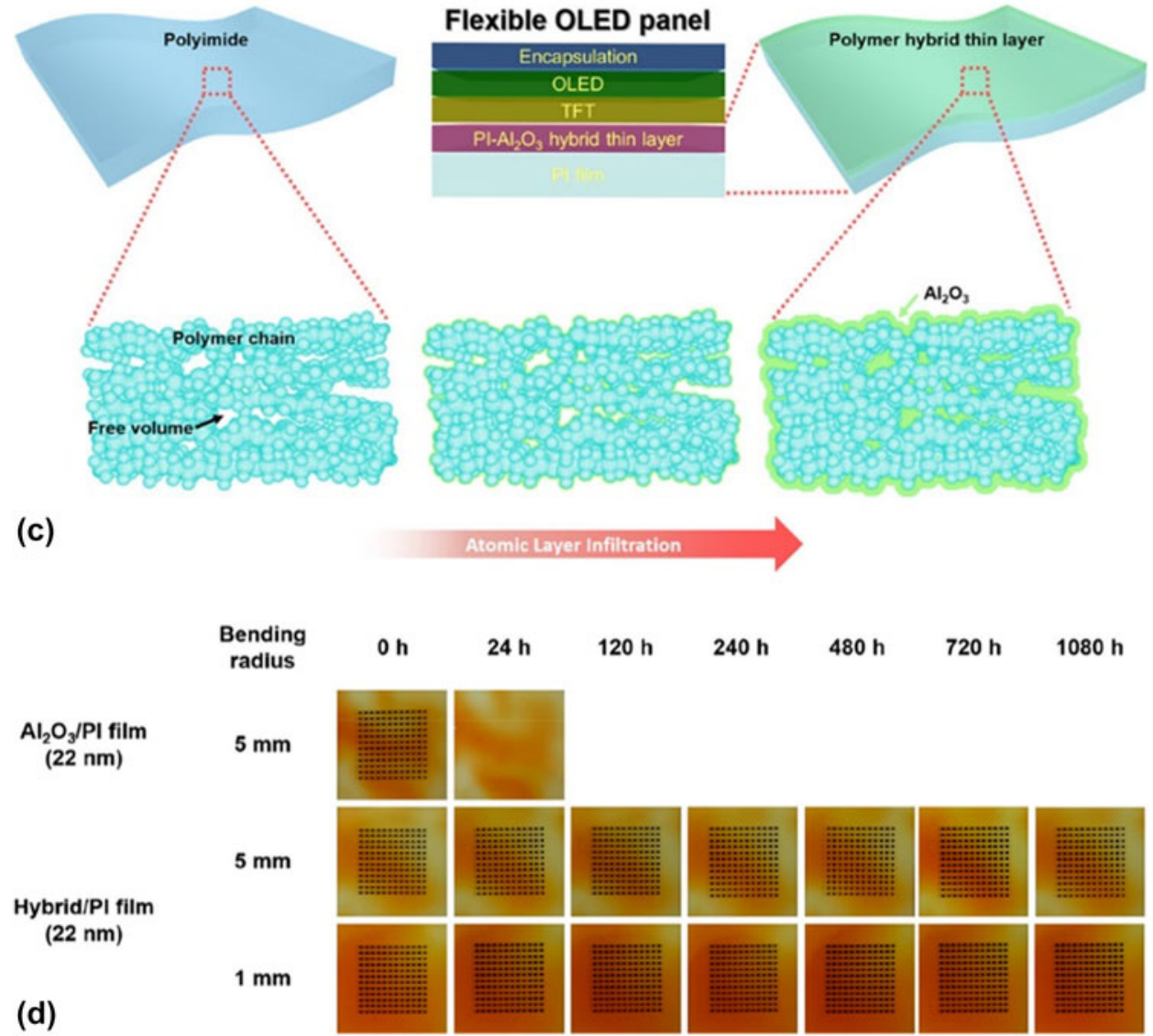

Figure 6: (a) Schematic depicting the "spring-like" nature of the alucone interlayer between the $\mathrm{Al}_{2} \mathrm{O}_{3} \mathrm{ALD}$ film and the Teflon FEP substrate; (b) compressive stress on $21 \mathrm{~nm} \mathrm{ALD-based} \mathrm{Al}_{2} \mathrm{O}_{3}$ versus alucone interlayer thickness on Teflon fluorinated ethylene propylene (FEP) substrates with thickness of 50 and $125 \mu \mathrm{m} ;$ (c) schematic illustration of fabrication of polymer hybrid thin layer via ALI method; (d) Ca dot corrosion tests for PI films after they were subjected to 10,000 bending cycles.

prepared with the CVD method, in which high temperature and catalysts are needed. Due to the simplicity of preparation process, Ag layer is more commonly adopted. Kwon et al. reported a dielectric-organic metal encapsulation structure to guarantee the reliability of flexible OLEDs [123], which is shown in Fig. 7(a). The thickness optimization of Ag layer is crucial for the device performance, in which a discontinuous Ag layer leads to the nonuniform heat transfer, whereas a thick layer leads to the low transparency. The kick point where the Ag film turned from discontinuous to continuous was shown photographically by the AFM or SEM, and it could also be deduced by the sharp decrease in the sheet resistance [57]. The overall structure was optimized via optical simulation via Matlab software, and it was found that the transmittance of $\mathrm{Al}_{2} \mathrm{O}_{3} / \mathrm{Ag} / \mathrm{Al}_{2} \mathrm{O}_{3}$ structure was $33 \%$ higher than that of the $\mathrm{Al}_{2} \mathrm{O}_{3} / \mathrm{Ag}$ structure due to the anti-reflection effect [123]. Finally, the nanocomposite organic layer was inserted to improve the flexibility further, and the $\mathrm{Al}_{2} \mathrm{O}_{3} / \mathrm{Ag} / \mathrm{Al}_{2} \mathrm{O}_{3} / \mathrm{S}-\mathrm{H}$ nanocomposite $/ \mathrm{Al}_{2} \mathrm{O}_{3}$ multilayer structure was obtained. As shown in Fig. 7(c), the infrared camera was used to observe 


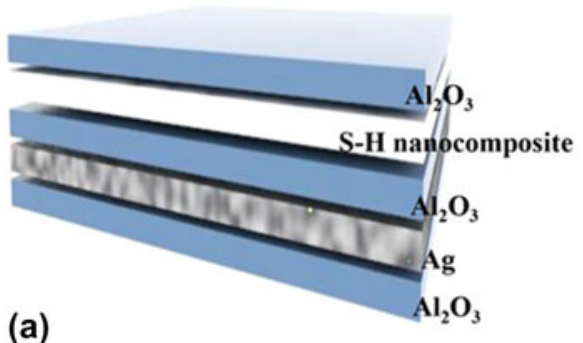

(a)

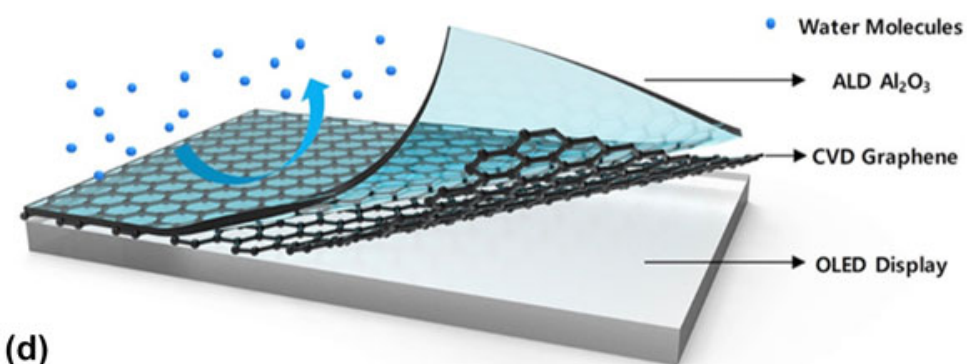

(b)

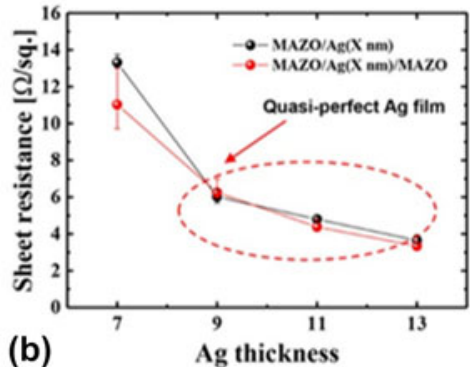

Ag thickness

(e)

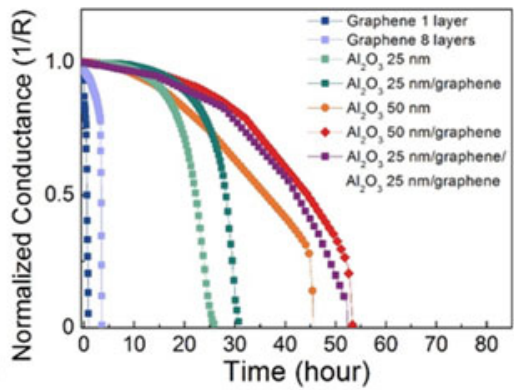

Figure 7: (a) Schematic of $\mathrm{Al}_{2} \mathrm{O}_{3} / \mathrm{Ag} / \mathrm{Al}_{2} \mathrm{O}_{3} / \mathrm{S}-\mathrm{H}$ nanocomposite/ $/ \mathrm{Al}_{2} \mathrm{O}_{3}$ barrier structure; (b) sheet resistance of $\mathrm{MAZO} / \mathrm{Ag}$ and $\mathrm{MAM}$ structures in relation to $\mathrm{Ag}$ thickness; (c) real-time temperature profiles of FOLEDs at an input power of $80 \mathrm{~mW}$ over time; (d) $\mathrm{Al}_{2} \mathrm{O}_{3} /$ graphene composite barrier layer; and (e) electrical Ca tests of different barrier structures.

the real-time temperature profiles of the OLEDs operated at the certain input power, and it was demonstrated that the insertion of the Ag layer in the multilayer structure helped conduct the heat out of the devices effectively, which prolonged the lifetime of the OLEDs. Besides, the excellent flexibility and barrier property of the dielectric-organic metal encapsulation structures were demonstrated before and after the bending tests.

The graphene possesses better heat conductivity and barrier property than those of $\mathrm{Ag}$ layer. Theoretically, the lattice constant of graphene is $2.47 \AA$, which is smaller than the size of $\mathrm{H}_{2} \mathrm{O}$ molecular (around $4.0 \AA$ ). It means that the perfect graphene layer can block the permeation of moisture effectively. To apply the artificial graphene films fabricated via CVD method to flexible electronics, Ruoff and colleagues transferred them to target substrate by an optimized process with the assistance of PMMA [124, 125]. As a good conductor, the insulator is needed to be inserted between the OLEDs and graphene, such as PDMS and PMMA. However, Karnik and colleagues revealed that the CVD-grown single-layer graphene had various defects, such as pinholes and cracks [126]. Seo et al. prepared the multi-stacked graphene films to form a defectsealed membrane, and it was found that the permeation rate decreased with the increase in the graphene layers [127], but which was still far from the requirements of OLEDs. As shown in Figs. 7(d) and 7(e), Nam et al. used the ALD-based $\mathrm{Al}_{2} \mathrm{O}_{3}$ to passivate the defects of the graphene films [128] and the barrier property improved significantly.

\section{ALD reactors and processes for TFE}

Notably, the ALD precursors are most aggressively reactive, which may lead to the degradation of the chemically active OLED materials. Thus, the chemical compatibility of these asmentioned ALD techniques with current OLED materials need to be discussed. Singh et al. investigated how the different oxidant precursors $\left(\mathrm{H}_{2} \mathrm{O}\right.$ and $\left.\mathrm{O}_{3}\right)$ affected the luminous performance and lifetime of OLEDs. In the experimental procedures, the pulse and purge duration for TMA was fixed at $0.3 \mathrm{~s}$ pulse and $0.75 \mathrm{~s}$ purge, and the pulse duration for the oxidant precursor ranged from 1 to $45 \mathrm{~s}$, and the purge duration maintained half of the pulse time [129]. Besides, the deposition temperature was set as $50{ }^{\circ} \mathrm{C}$. The results indicated that the $\mathrm{O}_{3}$-based process seemed to be more compatible with the OLEDs than the $\mathrm{H}_{2} \mathrm{O}$-based process [130]. As reported elsewhere, the activation energy for $\mathrm{Alq}_{3}$ hydrolysis (the emitting layer in OLEDs) is 35\% lower than that of the pure $\mathrm{Alq}_{3}$, and the hydrolyzed $\mathrm{Alq}_{3}$ would lead to the nonemissive area [131]. Thus, the ozone-based $\mathrm{Al}_{2} \mathrm{O}_{3}$ was deposited on the OLED surfaces directly, which can block the $\mathrm{H}_{2} \mathrm{O}$ diffusion in the later processes of $\mathrm{H}_{2} \mathrm{O}$-based $\mathrm{Al}_{2} \mathrm{O}_{3}$ films, and the blocking effect improves with the increasing $\mathrm{O}_{3}$-based $\mathrm{Al}_{2} \mathrm{O}_{3}$ film thickness. To avoid the direct contact with the precursors, Park et al. inserted a 3- $\mu$ m-thick organic buffer layer between OLED and $\mathrm{Al}_{2} \mathrm{O}_{3}$ barrier layer, and the pulse time of the precursors was optimized at the same time [62]. It can be found that several dark spots formed in the emitting image when the 
$\mathrm{H}_{2} \mathrm{O}$ pulse time was set as $1.43 \mathrm{~s}$, but no black spot was found when the pulse time was reduced to $0.5 \mathrm{~s}$ even without the buffer layer. In particular, to improve the performance of the OLED devices, the stacks consisting of materials with high and low refractive indexes would be deposited on the top of the devices, which serve as the optical functional layer to improve the light output. Thus, the chemically active OLED materials will not be exposed to the precursors directly, leading to the enhanced stability and reliability.

Various commercial ALD reactors have been reported for the continuous industrial production. Picosun (Espoo, Finland) has integrated the roll-to-roll module in the reaction chamber, which can be used for the flexible substrates with the width of $70 \mathrm{~mm}$. Similarly, Beneq (Espoo, Finland) has also published its roll-to-roll ALD system, and the web speed of which can reach $10 \mathrm{~m} / \mathrm{min}$. The Firebird ALD equipment invented by Veeco Company (Waltham, Massachusetts) can be utilized to fabricate the barrier layers and optoelectronics [132], and the substrates width can reach above $300 \mathrm{~mm}$. It is noted that the Infinity TM500 invented by Encapsulix (Aix-en-Provence, France) can be applied to the encapsulation of displays with width reaching G5.5 (1300 $\times$ $1500 \mathrm{~mm}^{2}$ ), and the WVTR of $25 \mathrm{~nm} \mathrm{Al} \mathrm{O}_{3}$ film reached $\sim 5$ $\times 10^{-4} \mathrm{~g} / \mathrm{m}^{2}$.day [133]. To further improve the deposition rate, more and more deposition chambers or units are integrated to improve the efficiency, and the related equipment has been reported by ASM International (Almere, Netherlands) [134], Eugene Technology (Yongin-si, Korea), and Leadmirco (Wuxi, China), which mainly serve for the semiconductor and solar cells.

However, with the continuous expansion of the panel size, the vacuum chamber of ALD reactors can no longer meet the requirements of large area and high throughput. Moreover, a long purge time is needed to clean the excessive precursor and by-product in the low-temperature process. Kwon et al. reported that the $\mathrm{Al}_{2} \mathrm{O}_{3}$ monolayer with the thickness of $\sim 60 \mathrm{~nm}$ performed the best barrier property, which could strike a balance between pinhole density and internal stress [94]. However, it is calculated that more than $4 \mathrm{~h}$ would be spent, which is far from the efficiency of the PE-CVD method. The spatial atomic layer deposition (SALD) is thought to be a potential method to solve this issue [135, 136]. Compared with the thermal ALD, the precursors will be injected into the reaction chamber continuously, and different precursors and the ambient will be separated by the inserted physical gas barriers. The substrate moves underneath the injectors cyclically, and the thickness can be controlled precisely by adjusting the cycle numbers. Choi et al. developed the high-throughput SALD system for the TFE of OLEDs, and it was applied to the $2 \mathrm{G}$ glass substrate $\left(370 \times 470 \mathrm{~mm}^{2}\right)$ with the deposition rate of $7 \mathrm{~nm} / \mathrm{min}$. The barrier property of the PEN substrates coated with 100 -nm-thick nanolaminates improved from $1.8 \times 10^{-3}$ to $6.9 \times 10^{-5} \mathrm{~g} / \mathrm{m}^{2}$.day [137]. Franke et al. developed their
SALD system integrated with a microwave plasma source, and the WVTR value of $50 \mathrm{~nm} \mathrm{Al}_{2} \mathrm{O}_{3}$ could reach $\sim 10^{-6} \mathrm{~g} / \mathrm{m}^{2}$. day [56]. Due to the simplicity of the linear track one, we also developed the modular injector integrated SALD apparatus, and the deposition rate reached $100 \mathrm{~nm} / \mathrm{min}$ with the nonuniformity around 2\% [138]. Besides, George and colleagues developed a modular rotating cylinder SALD reactor, in which the inner cylinder rotated with the flexible substrate and passed underneath the various spatially separated slits in the outer cylinder [139]. Poodt et al. developed the rotary SALD equipment and applied it to the passivation of silicon solar cells, and the drastic increase in the solar cell efficiency was found [140]. Similar commercial equipment such as the InPassion ALD invented by SoLayTec has also been reported [141], in which more than 4 deposition units are integrated, resulting in the production efficiency of 4500 wafers per hour. Meanwhile, ASTRal and TNO had developed the roll-to-roll SALD equipment, which can be applied in the encapsulation of flexible electronics with the width more than $300 \mathrm{~mm}[142,143,144,145]$.

Except for the limitation of substrate size and low deposition rate, the demand of low-temperature process for polymer substrates requires that only the precursors with high reactivity (such as TMA, DEZ, and $\mathrm{TiCl}_{4}$ ) can be adopted. However, the oxides will be deposited on the chamber walls and masks at the same time, which are hard to be removed, leading to the particle contamination of the barrier structures after a long period. One of the solutions to solve this problem is to synthesize the new precursors for the oxides such as $\mathrm{SiO}_{2}$, which ought to possess high reactivity and adequate saturated vapor pressure, and the by-product is easy to be eliminated. Besides, the $\mathrm{SiO}_{2}$ film deposited on the chamber walls and masks are easy to be removed by introducing the corrosive gas, which can promote the cleanliness of the chamber. Another way is to develop the plasma-enhanced atomic layer deposition (PEALD) method, in which the oxidant (such as $\mathrm{O}_{2}, \mathrm{~N}_{2}$ ) can be activated by the electric fields, and the process temperature can be lowered to the room temperature. It has been successfully applied in the preparation of $\mathrm{AlN}[146,147]$ and $\mathrm{SiO}_{2}$ [148], and the SALD method can also be integrated to increase the deposition rate [49]. Compared with the thermal ALD, denser films can be obtained via PEALD, and the excellent barrier property of the monolayer or laminated encapsulation structures $[59,77,116]$ has been demonstrated.

\section{Summary and outlook}

OLEDs are attractive for flexible displays; yet, the reliability is of great challenge to overcome pinholes and crystallization, cracks, and overheated through barrier layers. The ALD-based TFE has emerged as a powerful method to solve the existing issues. The monolayer and composite structures fabricated via 
ALD can decouple the pinhole defects, and the nanolaminates possess superior water-corrosion-resistant property and inhibit the crystallization. Moreover, hybrid laminated structures can reduce internal stress and improve the flexibility, and an additional heat sink system is embedded to transfer the heat out to avoid the thermal aging. Besides, the SALD and PEALD methods have been proposed to improve the deposition rate and to extend the range of the precursors that can be utilized.

Nevertheless, there are some remaining challenges to be addressed toward further flexibility and potential stretchable displays. With the thickness continuing to go down, the encapsulation structures have to be further optimized with consideration of optical emittance, barrier resistance, and mechanical robustness. A database containing different inorganic or organic materials needs to be built based on the different experimental processes, which covers the parameters of mechanical, optical, thermal, and barrier properties corresponding to different processes. The interfaces between multilayer hybrid films need more accurate theoretical simulations with interface consideration. Moreover, the barrier structures are expected to replace the original capping layer of the OLEDs, leading to the simplified device structures, and the moistures can be blocked effectively.

Another obstacle currently is how to fabricate large-scale organic layer with accurate thickness control and good throughput, as organic layers play an important role in the design of the ultra-flexible barriers. Inspired by the SALD methods, the oxidant precursor can be replaced by the organic materials, and the spatial molecular layer deposition (SMLD) will be achieved. However, the isolation between different precursors in the SMLD will be more complex due to high viscosity of organic precursors. A more reliable method to fabricate the organic layers is ink-jet printing, in which lots of nozzles can be integrated to satisfy the requirement of largearea substrates. Besides, the future stretchable electronics will require TFE as well, and the organic-inorganic hybrid layers with excellent tensile properties need to be developed.

Another issue ALD currently faces urgently is the selfclean. Current ALD components have strongly relied on $\mathrm{Al}_{2} \mathrm{O}_{3}$ and other hard-to-etch materials. It is important to have $\mathrm{SiO}_{x}$ investigated and be able to grow with low temperature on large scale. The ALD precursor development also needs to be addressed. On the other hand, in the preparation process of the barrier structures, the masks are necessary to protect the electrodes from being covered by the dielectric films. Meanwhile, they also play an important role in the fabrication of the patterned structures for the OLEDs, especially for the MicroLED. Therefore, the frequent cleaning of masks or adopting the thin film deposition processes, which can realize the in situ self-cleaning, is necessary to avoid the particle contamination. Besides, how to promote the high accuracy of linewidth resolution on the edge area is of great importance.
The area-selective ALD is expected to streamline the process flow and solve the broken inorganic layers with small folding radius, and TFEs only deposit where they are needed.

The design of the encapsulation structures of the flexible OLEDs is a systematic and complex project, and the ALD method will play a more important role in the future due to its unique assets.

\section{Acknowledgments}

This work was supported by the National Natural Science Foundation of China (51835005, 51575217, and 51702106). The authors acknowledge the Flexible Electronics Research Center of Huazhong University of Science and Technology. The authors also thank Yinghao Zhang and Yuan Lin from Huazhong University of Science and Technology and Dr. Jing Huang from Wuhan China Star Optoelectronics Technology Co., Ltd., for the instructive discussions.

\section{References}

1. G. Blasse and A. Bril: A new phosphor for flying-spot cathode ray tubes for color television: Yellow emitting $\mathrm{Y}_{3} \mathrm{Al}_{5} \mathrm{O}_{12}-\mathrm{Ce}^{3+}$. Appl. Phys. Lett. 11, 53 (1967).

2. D.J. Channin and D.E. Carlson: Rapid turn-off in triode optical gate liquid crystal devices. Appl. Phys. Lett. 28, 300 (1976).

3. J. Meunier, P. Belenguer, and J.P. Boeuf: Numerical model of an ac plasma display panel cell in neon-xenon mixtures. J. Appl. Phys. 78, 731 (1995).

4. J.H. Burroughes, D.D.C. Bradley, A.R. Brown, R.N. Marks, K. Mackay, R.H. Friend, P.L. Burns, and A.B. Holmes: Lightemitting diodes based on conjugated polymers. Nature 347, 539 (1990).

5. S. Reineke, F. Lindner, G. Schwartz, N. Seidler, K. Walzer, B. Lüssem, and K. Leo: White organic light-emitting diodes with fluorescent tube efficiency. Nature 459, 234 (2009).

6. C. Adachi, K. Nagai, and N. Tamoto: Molecular design of hole transport materials for obtaining high durability in organic electroluminescent diodes. Appl. Phys. Lett. 66, 2679 (1995).

7. S-J. Su: Takayuki chiba, takashi takeda and junji kido: Pyridinecontaining triphenylbenzene derivatives with high electron mobility for highly efficient phosphorescent. OLEDs Adv. Mater. 20, 2125 (2008).

8. A. Curioni, M. Boero, and W. Andreoni: $\mathrm{Alq}_{3}: \mathrm{Ab}$ initio calculations of its structural and electronic properties in neutral and charged states. Chem. Phys. Lett. 294, 263 (1998).

9. V.V. Jarikov and D.Y. Kondakov: Studies of the degradation mechanism of organic light-emitting diodes based on tris(8quinolinolate)aluminum Alq and 2-tert-butyl-9,10-di(2naphthyl)anthracene TBADN. J. Appl. Phys. 105, 034905 (2009).

10. J. Kido, K. Hongawa, K. Okuyama, and K. Nagai: White lightemitting organic electroluminescent devices using the poly $(\mathrm{N}$ - 
vinylcarbazole) emitter layer doped with three fluorescent dyes. Appl. Phys. Lett. 64, 815 (1994).

11. M. Pope, H.P. Kallmann, and P. Magnante: Electroluminescence in organic crystals. J. Chem. Phys. 38, 2042 (1963).

12. C.W. Tang and S.A. VanSlyke: Organic electroluminescent diodes. Appl. Phys. Lett. 51, 913 (1987).

13. J-J. Kim, M-K. Han, and Y-Y. Noh: Flexible OLEDs and organic electronics. Semicond. Sci. Technol. 26, 030301 (2011).

14. R. Abbel, I. de Vries, A. Langen, G. Kirchner, H. t'Mannetje, H. Gorter, J. Wilson, and P. Groen: Toward high volume solution based roll-to-roll processing of OLEDs. J. Mater. Res. 32, 2219 (2017)

15. A.P. Ghosh, L.J. Gerenser, C.M. Jarman, and J.E. Fornalik: Thin-film encapsulation of organic light-emitting devices. Appl. Phys. Lett. 86, 223503 (2005).

16. J-S. Park, H. Chae, H.K. Chung, and S.I. Lee: Thin film encapsulation for flexible AM-OLED: A review. Semicond. Sci. Technol. 26, 034001 (2011).

17. S. Vera and L. Moro: Encapsulation requirements to enable stable organic ultra-thin and stretchable devices. J. Mater. Res. 33, 1925 (2018).

18. W. Keuning, P. van de Weijer, H. Lifka, W.M.M. Kessels, and M. Creatore: Cathode encapsulation of organic light emitting diodes by atomic layer deposited $\mathrm{Al}_{2} \mathrm{O}_{3}$ films and $\mathrm{Al}_{2} \mathrm{O}_{3} / \mathrm{a}-\mathrm{SiN}_{x}: \mathrm{H}$ stacks. J. Vac. Sci. Technol., A 30, 01A131 (2011).

19. H. Uchida and M. Yamashita: Pinhole defect evaluation of TiN films prepared by dry coating process. Vacuum 59, 321 (2000).

20. V. Miikkulainen, M. Leskelä, M. Ritala, and R.L. Puurunen: Crystallinity of inorganic films grown by atomic layer deposition: Overview and general trends. J. Appl. Phys. 113, 021301 (2013).

21. Z. Wan, T.F. Zhang, H-B-R. Lee, J.H. Yang, W.C. Choi,

B. Han, K.H. Kim, and S-H. Kwon: Improved corrosion resistance and mechanical properties of $\mathrm{CrN}$ hard coatings with an atomic layer deposited $\mathrm{Al}_{2} \mathrm{O}_{3}$ interlayer. ACS Appl. Mater. Interfaces. 7, 26716 (2015).

22. C-T. Chou, P-W. Yu, M-H. Tseng, C-C. Hsu, J-J. Shyue, C-C. Wang, and F-Y. Tsai: Transparent conductive gaspermeation barriers on plastics by atomic layer deposition. $A d v$. Mater. 25, 1750 (2013)

23. S-H. Jen, J.A. Bertrand, and S.M. George: Critical tensile and compressive strains for cracking of $\mathrm{Al}_{2} \mathrm{O}_{3}$ films grown by atomic layer deposition. J. Appl. Phys. 109, 084305 (2011).

24. O.M.E. Ylivaara, X. Liu, L. Kilpi, J. Lyytinen, D. Schneider, M. Laitinen, J. Julin, S. Ali, S. Sintonen, M. Berdova, E. Haimi, T. Sajavaara, H. Ronkainen, H. Lipsanen, J. Koskinen, S-P. Hannula, and R.L. Puurunen: Aluminum oxide from trimethylaluminum and water by atomic layer deposition: The temperature dependence of residual stress, elastic modulus hardness and adhesion. Thin Solid Films 552, 124 (2014).

25. J. Lewis: Material challenge for flexible organic devices. Mater. Today 9, 38 (2006).
26. S-H. Jen, S.M. George, R.S. McLean, and P.F. Carcia: Alucone interlayers to minimize stress caused by thermal expansion mismatch between $\mathrm{Al}_{2} \mathrm{O}_{3}$ films and Teflon substrates. ACS Appl. Mater. Interfaces 5, 1165 (2013).

27. P.E. Burrows, G.L. Graff, M.E. Gross, P.M. Martin, M. Hall, E. Mast, C.C. Bonham, W.D. Bennett, L.A. Michalski,

M.S. Weaver, J.J. Brown, D. Fogarty, and L.S. Sapochak: Gas permeation and lifetime tests on polymer-based barrier coatings. Proc. SPIE 4105, 75 (2001).

28. J.H. Kwon, E. Kim, H-G. Im, B-S. Bae, K.S. Chang, S-H.K. Park, and K.C. Choi: Metal-containing thin-film encapsulation with flexibility and heat transfer. J. Inf. Disp. 16, 123 (2015)

29. G. Vamvounis, H. Aziz, N-X. Hu, and Z.D. Popovic: Temperature dependence of operational stability of organic light emitting diodes based on mixed emitter layers. Synth. Met. 143, 69 (2004).

30. A.L. Moore and L. Shi: Emerging challenges and materials for thermal management of electronics. Mater. Today 17, 163 (2014).

31. J. Park, H. Ham, and C. Park: Heat transfer property of thinfilm encapsulation for OLEDs. Org. Electron. 12, 227 (2011).

32. M. Steven: George: Atomic layer deposition: An overview. Chem. Rev. 110, 111 (2010)

33. A.E. Short, S.V. Pamidi, Z.E. Bloomberg, Y. Li, and M.D. Losego: Atomic layer deposition (ALD) of subnanometer inorganic layers on natural cotton to enhance oil sorption performance in marine environments. J. Mater. Res. 34, 563 (2019).

34. Y. Duan, Y-Q. Yang, Z. Chen, T. Ye, and Y-F. Liu: Recent progress on thin-film encapsulation technologies for organic electronic devices. Opt. Commun. 362, 43 (2016).

35. S. Lee, J-H. Han, S-H. Lee, G-H. Baek, and J-S. Park: Review of organic/inorganic thin film encapsulation by atomic layer deposition for a flexible OLED display. JOM 71, 197 (2019).

36. Y.G. Tropsha and N.G. Harvey: Activated rate theory treatment of oxygen and water transport through silicon oxide/ poly(ethylene terephthalate) composite barrier structures. J. Phys. Chem. B 101, 2259 (1997).

37. S. Ahn, Y. Kim, S. Kang, K. Im, and H. Lim: Low-temperatureatomic-layer-deposition of $\mathrm{SiO}_{2}$ using various organic precursors. J. Vac. Sci. Technol., A 35, 01B131 (2016).

38. Y-S. Lee, D-w. Choi, B. Shong, S. Oh, and J-S. Park: Low temperature atomic layer deposition of $\mathrm{SiO}_{2}$ thin films using diisopropylaminosilane and ozone. Ceram. Int. 43, 2095 (2017).

39. B.B. Burton, M.P. Boleslawski, A.T. Desombre, and S.M. George: Rapid $\mathrm{SiO}_{2}$ atomic layer deposition using tris(tertpentoxy)silanol. Chem. Mater. 20, 7031 (2008).

40. R.A. Ovanesyan, D.M. Hausmann, and S. Agarwal: Lowtemperature conformal atomic layer deposition of $\mathrm{SiN}_{x}$ films using $\mathrm{Si}_{2} \mathrm{Cl}_{6}$ and $\mathrm{NH}_{3}$ plasma. ACS Appl. Mater. Interfaces 7, 10806 (2015). 
41. E.K. Park, S. Kim, J. Heo, and H.J. Kim: Electrical evaluation of crack generation in $\mathrm{SiN}_{x}$ and $\mathrm{SiO}_{x} \mathrm{~N}_{y}$ thin-film encapsulation layers for OLED displays. Appl. Surf. Sci. 370, 126 (2016).

42. P.F. Carcia, R.S. McLean, M.D. Groner, A.A. Dameron, and S.M. George: Gas diffusion ultrabarriers on polymer substrates using $\mathrm{Al}_{2} \mathrm{O}_{3}$ atomic layer deposition and $\mathrm{SiN}$ plasma-enhanced chemical vapor deposition. J. Appl. Phys. 106, 023533 (2009).

43. T. Maindron, T. Jullien, and A. André: Defect analysis in low temperature atomic layer deposited $\mathrm{Al}_{2} \mathrm{O}_{3}$ and physical vapor deposited $\mathrm{SiO}$ barrier films and combination of both to achieve high quality moisture barriers. J. Vac. Sci. Technol., A 34, 031513 (2016).

44. M. Li, D. Gao, S. Li, Z. Zhou, J. Zou, H. Tao, L. Wang, M. Xu, and J. Peng: Realization of highly-dense $\mathrm{Al}_{2} \mathrm{O}_{3}$ gas barrier for top-emitting organic light-emitting diodes by atomic layer deposition. RSC Adv. 5, 104613 (2015).

45. Y-Q. Yang and Y. Duan: Optimization of $\mathrm{Al}_{2} \mathrm{O}_{3}$ films deposited by ALD at low temperatures for OLED encapsulation. J. Phys. Chem. C 118, 18783 (2014).

46. A. Holmqvist, T. Törndahl, and S. Stenström: A model-based methodology for the analysis and design of atomic layer deposition processes-Part I: Mechanistic modelling of continuous flow reactors. Chem. Eng. Sci. 81, 260 (2012).

47. D.R. Lide and W.M.M. Haynes: CRC Handbook of Chemistry and Physics, 1st Student ed. (CRC Press Inc., Boca Raton, 1998).

48. M.D. Groner, S.M. George, R.S. McLean, and P.F. Carcia: Gas diffusion barriers on polymers using $\mathrm{Al}_{2} \mathrm{O}_{3}$ atomic layer deposition. Appl. Phys. Lett. 88, 051907 (2006).

49. Y. Yong-Qiang, D. Yu, D. Ya-Hui, W. Xiao, C. Ping, Y. Dan, S. Feng-Bo, and X. Kai-wen: High barrier properties of transparent thin-film encapsulations for top emission organic light-emitting diodes. Org. Electron. 15, 1120 (2014).

50. Y-Q. Yang, Y. Duan, P. Chen, F-B. Sun, Y-H. Duan, X. Wang, and D. Yang: Realization of thin film encapsulation by atomic layer deposition of $\mathrm{Al}_{2} \mathrm{O}_{3}$ at low temperature. J. Phys. Chem. C 117, 20308 (2013).

51. Y. Duan, F. Sun, Y. Yang, P. Chen, D. Yang, Y. Duan, and X. Wang: Thin-film barrier performance of zirconium oxide using the low-temperature atomic layer deposition method. ACS Appl. Mater. Interfaces 6, 3799 (2014).

52. H. Wang, Z. Wang, X. Xu, Y. Liu, C. Chen, P. Chen, W. Hu, and Y. Duan: Multiple short pulse process for low-temperature atomic layer deposition and its transient steric hindrance. Appl. Phys. Lett. 114, 201902 (2019).

53. H. Wang, Y. Liu, H. Liu, Z. Chen, P. Xiong, X. Xu, F. Chen, K. Li, and Y. Duan: Effect of various oxidants on reaction mechanisms, self-limiting natures and structural characteristics of $\mathrm{Al}_{2} \mathrm{O}_{3}$ films grown by atomic layer deposition. Adv. Mater. Interfaces 5, 1701248 (2018).

54. S.J. Yun, Y-W. Ko, and J.W. Lim: Passivation of organic lightemitting diodes with aluminum oxide thin films grown by plasma-enhanced atomic layer deposition. Appl. Phys. Lett. 85 , 4896 (2004).

55. L. Hoffmann, D. Theirich, S. Pack, F. Kocak, D. Schlamm, T. Hasselmann, H. Fahl, A. Räupke, H. Gargouri, and T. Riedl: Gas diffusion barriers prepared by spatial atmospheric pressure plasma enhanced ALD. ACS Appl. Mater. Interfaces 9, 4171 (2017).

56. S. Franke, M. Baumkötter, C. Monka, S. Raabe, R. Caspary, H-H. Johannes, W. Kowalsky, S. Beck, A. Pucci, and H. Gargouri: Alumina films as gas barrier layers grown by spatial atomic layer deposition with trimethylaluminum and different oxygen sources. J. Vac. Sci. Technol., A 35, $01 \mathrm{~B} 117$ (2016).

57. J.H. Kwon, Y. Jeon, and K.C. Choi: Robust transparent and conductive gas diffusion multibarrier based on $\mathrm{Mg}$ - and $\mathrm{Al}$ doped $\mathrm{ZnO}$ as indium tin oxide-free electrodes for organic electronics. ACS Appl. Mater. Interfaces 10, 32387 (2018).

58. J. Oh, S. Shin, J. Park, G. Ham, and H. Jeon: Characteristics of $\mathrm{Al}_{2} \mathrm{O}_{3} / \mathrm{ZrO}_{2}$ laminated films deposited by ozone-based atomic layer deposition for organic device encapsulation. Thin Solid Films 599, 119 (2016)

59. L.H. Kim, K. Kim, S. Park, Y.J. Jeong, H. Kim, D.S. Chung, S.H. Kim, and C.E. Park: $\mathrm{Al}_{2} \mathrm{O}_{3} / \mathrm{TiO}_{2}$ nanolaminate thin film encapsulation for organic thin film transistors via plasmaenhanced atomic layer deposition. ACS Appl. Mater. Interfaces 6, 6731 (2014).

60. J.H. Kwon, Y. Jeon, S. Choi, J.W. Park, H. Kim, and K.C. Choi Functional design of highly robust and flexible thin-film encapsulation composed of quasi-perfect sublayers for transparent, flexible displays. ACS Appl. Mater. Interfaces $\mathbf{9}$, 43983 (2017).

61. E. Kim, Y. Han, W. Kim, K.C. Choi, H-G. Im, and B-S. Bae: Thin film encapsulation for organic light emitting diodes using a multi-barrier composed of $\mathrm{MgO}$ prepared by atomic layer deposition and hybrid materials. Org. Electron. 14, 1737 (2013).

62. S-H.K. Park, J. Oh, C-S. Hwang, J-I. Lee, Y.S. Yang, and H.Y. Chu: Ultrathin film encapsulation of an OLED by ALD. Electrochem. Solid-State Lett. 8, H21 (2005).

63. S-H.K. Park, J. Oh, C-S. Hwang, J-I. Lee, Y.S. Yang, H.Y. Chu, and K-Y. Kang: Ultra thin film encapsulation of organic light emitting diode on a plastic substrate. ETRI J. 27, 545 (2005).

64. S. Pasieczna-Patkowska and J. Ryczkowski: Spectroscopic studies of alumina-supported nickel catalysts precursors: Part I. Catalysts prepared from acidic solutions. Appl. Surf. Sci. 253, 5910 (2007).

65. S.K. Kim, C.S. Hwang, S-H.K. Park, and S.J. Yun: Comparison between $\mathrm{ZnO}$ films grown by atomic layer deposition using $\mathrm{H}_{2} \mathrm{O}$ or $\mathrm{O}_{3}$ as oxidant. Thin Solid Films 478, 103 (2005).

66. D-y. Zhang, P-p. Wang, R-i. Murakami, and X-P. Song: Firstprinciples simulation, and experimental evidence for improvement of transmittance in $\mathrm{ZnO}$ films. Prog. Nat. Sci.: Mater. Int. 21, 40 (2011). 
67. D.R.G. Mitchell, D.J. Attard, and G. Triani: Transmission electron microscopy studies of atomic layer deposition $\mathrm{TiO}_{2}$ films grown on silicon. Thin Solid Films 441, 85 (2003).

68. D.M. Hausmann and R.G. Gordon: Surface morphology and crystallinity control in the atomic layer deposition (ALD) of hafnium and zirconium oxide thin films. J. Cryst. Growth 249, 251 (2003).

69. S. Ueno, Y. Konishi, and K. Azuma: Development of an intermediate layer for highly reliable encapsulation structures for OLED displays. ECS J. Solid State Sci. Technol. 5, R21 (2016).

70. O.M.E. Ylivaara, L. Kilpi, X. Liu, S. Sintonen, S. Ali, M. Laitinen, J. Julin, E. Haimi, T. Sajavaara, H. Lipsanen, S-P. Hannula, H. Ronkainen, and R.L. Puurunen: Aluminum oxide/titanium dioxide nanolaminates grown by atomic layer deposition: Growth and mechanical properties. J. Vac. Sci. Technol., A. 35, 01B105 (2016).

71. R. Viter, I. Baleviciute, A. Abou Chaaya, L. Mikoliunaite, Z. Balevicius, A. Ramanavicius, A. Zalesska, V. Vataman, V. Smyntyna, Z. Gertnere, D. Erts, P. Miele, and M. Bechelany: Optical properties of ultrathin $\mathrm{Al}_{2} \mathrm{O}_{3} / \mathrm{ZnO}$ nanolaminates. Thin Solid Films 594, 96 (2015).

72. R. Chen, J-L. Lin, W-J. He, C-L. Duan, P. Qi, X-L. Wang, and

B. Shan: Spatial atomic layer deposition of $\mathrm{ZnO} / \mathrm{TiO}_{2}$ nanolaminates. J. Vac. Sci. Technol., A. 34, 051502 (2016).

73. I. Iatsunskyi, E. Coy, R. Viter, G. Nowaczyk, M. Jancelewicz, I. Baleviciute, K. Załeski, and S. Jurga: Study on structural, mechanical, and optical properties of $\mathrm{Al}_{2} \mathrm{O}_{3}-\mathrm{TiO}_{2}$ nanolaminates prepared by atomic layer deposition. J. Phys. Chem. C 119, 20591 (2015).

74. J.W. Elam, Z.A. Sechrist, and S.M. George: $\mathrm{ZnO} / \mathrm{Al}_{2} \mathrm{O}_{3}$ nanolaminates fabricated by atomic layer deposition: Growth and surface roughness measurements. Thin Solid Films 414, 43 (2002).

75. J. Meyer, P. Görrn, F. Bertram, S. Hamwi, T. Winkler, H-H. Johannes, T. Weimann, P. Hinze, T. Riedl, and W. Kowalsky: $\mathrm{Al}_{2} \mathrm{O}_{3} / \mathrm{ZrO}_{2}$ nanolaminates as ultrahigh gasdiffusion barriers-A strategy for reliable encapsulation of organic electronics. Adv. Mater. 21, 1845 (2009).

76. J. Meyer, D. Schneidenbach, T. Winkler, S. Hamwi,

T. Weimann, P. Hinze, S. Ammermann, H.H. Johannes,

T. Riedl, and W. Kowalsky: Reliable thin film encapsulation for organic light emitting diodes grown by low-temperature atomic layer deposition. Appl. Phys. Lett. 94, 233305 (2009).

77. S. Lee, H. Choi, S. Shin, J. Park, G. Ham, H. Jung, and H. Jeon: Permeation barrier properties of an $\mathrm{Al}_{2} \mathrm{O}_{3} / \mathrm{ZrO}_{2}$ multilayer deposited by remote plasma atomic layer deposition. Curr. Appl. Phys. 14, 552 (2014).

78. J. Meyer, H. Schmidt, W. Kowalsky, T. Riedl, and A. Kahn: The origin of low water vapor transmission rates through $\mathrm{Al}_{2} \mathrm{O}_{3} / \mathrm{ZrO}_{2}$ nanolaminate gas-diffusion barriers grown by atomic layer deposition. Appl. Phys. Lett. 96, 243308 (2010).
79. J-H. Choi, Y-M. Kim, Y-W. Park, T-H. Park, J-W. Jeong, H-J. Choi, E-H. Song, J-W. Lee, C-H. Kim, and B-K. Ju: Highly conformal $\mathrm{SiO}_{2} / \mathrm{Al}_{2} \mathrm{O}_{3}$ nanolaminate gas-diffusion barriers for large-area flexible electronics applications. Nanotechnology 21, 475203 (2010)

80. A.A. Dameron, S.D. Davidson, B.B. Burton, P.F. Carcia, R.S. McLean, and S.M. George: Gas diffusion barriers on polymers using multilayers fabricated by $\mathrm{Al}_{2} \mathrm{O}_{3}$ and rapid $\mathrm{SiO}_{2}$ atomic layer deposition. J. Phys. Chem. C 112, 4573 (2008).

81. M.K. Tripp, C. Stampfer, D.C. Miller, T. Helbling, C.F. Herrmann, C. Hierold, K. Gall, S.M. George, and V.M. Bright: The mechanical properties of atomic layer deposited alumina for use in micro- and nano-electromechanical systems. Sens. Actuators, A 130-131, 419 (2006).

82. A. Bulusu, A. Singh, C.Y. Wang, A. Dindar, C. FuentesHernandez, H. Kim, D. Cullen, B. Kippelen, and S. Graham: Engineering the mechanical properties of ultrabarrier films grown by atomic layer deposition for the encapsulation of printed electronics. J. Appl. Phys. 118, 085501 (2015).

83. A. Behrendt, J. Meyer, P. van de Weijer, T. Gahlmann, R. Heiderhoff, and T. Riedl: Stress management in thin-film gas-permeation barriers. ACS Appl. Mater. Interfaces 8, 4056 (2016).

84. S. Lee, J-Y. Kwon, D. Yoon, H. Cho, J. You, Y.T. Kang, D. Choi, and W. Hwang: Bendability optimization of flexible optical nanoelectronics via neutral axis engineering. Nanoscale Res. Lett. 7, 256 (2012).

85. N. Kim and S. Graham: Development of highly flexible and ultra-low permeation rate thin-film barrier structure for organic electronics. Thin Solid Films 547, 57 (2013).

86. L. Wang, C. Ruan, M. Li, J. Zou, T. Hong, J. Peng, and M. Xu: Enhanced moisture barrier performance for ALD-encapsulated OLEDs by introducing an organic protective layer. J. Mater. Chem. C 5, 4017 (2017).

87. H. Klumbies, P. Schmidt, M. Hähnel, A. Singh, U. Schroeder C. Richter, T. Mikolajick, C. Hoßbach, M. Albert, W.J. Bartha, K. Leo, and L. Müller-Meskamp: Thickness dependent barrier performance of permeation barriers made from atomic layer deposited alumina for organic devices. Org. Electron. 17, 138 (2015).

88. J.H. Kwon, Y. Jeon, S. Choi, H. Kim, and K.C. Choi: Synergistic gas diffusion multilayer architecture based on the nanolaminate and inorganic-organic hybrid organic layer. J. Inf. Disp. 19, 135 (2018).

89. S-W. Seo, E. Jung, C. Lim, H. Chae, and S.M. Cho: Water permeation through organic-inorganic multilayer thin films. Thin Solid Films 520, 6690 (2012).

90. P. van de Weijer, P.C.P. Bouten, S. Unnikrishnan, H.B. Akkerman, J.J. Michels, and T.M.B. van Mol: Highperformance thin-film encapsulation for organic light-emitting diodes. Org. Electron. 44, 94 (2017). 
91. M.S. Weaver, L.A. Michalski, K. Rajan, M.A. Rothman, J.A. Silvernail, J.J. Brown, P.E. Burrows, G.L. Graff, M.E. Gross, P.M. Martin, M. Hall, E. Mast, C. Bonham, W. Bennett, and M. Zumhoff: Organic light-emitting devices with extended operating lifetimes on plastic substrates. Appl. Phys. Lett. 81, 2929 (2002).

92. E.G. Jeong, S. Kwon, J.H. Han, H-G. Im, B-S. Bae, and K.C. Choi: A mechanically enhanced hybrid nano-stratified barrier with a defect suppression mechanism for highly reliable flexible OLEDs. Nanoscale 9, 6370 (2017)

93. W.M. Yun, J. Jang, S. Nam, L.H. Kim, S.J. Seo, and C.E. Park: Thermally evaporated $\mathrm{SiO}$ thin films as a versatile interlayer for plasma-based OLED passivation. ACS Appl. Mater. Interfaces 4, 3247 (2012).

94. J.H. Kwon, E.G. Jeong, Y. Jeon, D-G. Kim, S. Lee, and K.C. Choi: Design of highly water resistant, impermeable, and flexible thin-film encapsulation based on inorganic/organic hybrid layers. ACS Appl. Mater. Interfaces 11, 3251 (2019).

95. J. Wu, F. Fei, C. Wei, X. Chen, S. Nie, D. Zhang, W. Su, and Z. Cui: Efficient multi-barrier thin film encapsulation of OLED using alternating $\mathrm{Al}_{2} \mathrm{O}_{3}$ and polymer layers. RSC $A d v$. 8, 5721 (2018).

96. N.G. Semaltianos: Spin-coated PMMA films. Microelectron. J. 38, 754 (2007).

97. J. Liang, F. Kohsaka, T. Matsuo, X. Li, and T. Ueda: Improved bi-layer lift-off process for MEMS applications. Microelectron. Eng. 85, 1000 (2008).

98. M.E. Alf, A. Asatekin, M.C. Barr, S.H. Baxamusa, H. Chelawat, G. Ozaydin-Ince, C.D. Petruczok, R. Sreenivasan, W.E. Tenhaeff, N.J. Trujillo, S. Vaddiraju, J. Xu, and

K.K. Gleason: Chemical vapor deposition of conformal, functional, and responsive polymer films. Adv. Mater. 22, 1993 (2010).

99. H. Zhou and S.F. Bent: Fabrication of organic interfacial layers by molecular layer deposition: Present status and future opportunities. J. Vac. Sci. Technol., A 31, 040801 (2013).

100. N.M. Adamczyk, A.A. Dameron, and S.M. George: Molecular layer deposition of $\operatorname{poly}(p$-phenylene terephthalamide) films using terephthaloyl chloride and p-phenylenediamine. Langmuir 24, 2081 (2008)

101. M. Putkonen, J. Harjuoja, T. Sajavaara, and L. Niinistö: Atomic layer deposition of polyimide thin films. J. Mater. Chem. 17, 664 (2007)

102. P.W. Loscutoff, H. Zhou, S.B. Clendenning, and S.F. Bent: formation of organic nanoscale laminates and blends by molecular layer deposition. ACS Nano 4, 331 (2010).

103. T. Yoshimura, S. Ito, T. Nakayama, and K. Matsumoto: Orientation-controlled molecule-by-molecule polymer wire growth by the carrier-gas-type organic chemical vapor deposition and the molecular layer deposition. Appl. Phys. Lett. 91, 033103 (2007).
104. A.A. Dameron, D. Seghete, B.B. Burton, S.D. Davidson, A.S. Cavanagh, J.A. Bertrand, and S.M. George: Molecular layer deposition of alucone polymer films using trimethylaluminum and ethylene glycol. Chem. Mater. 20, 3315 (2008).

105. Q. Peng, B. Gong, R.M. VanGundy, and G.N. Parsons:

"Zincone" zinc oxide-organic hybrid polymer thin films formed by molecular layer deposition. Chem. Mater. 21, 820 (2009).

106. S. Cho, G. Han, K. Kim, and M.M. Sung: High-performance two-dimensional polydiacetylene with a hybrid inorganic-organic structure. Angew. Chem., Int. Ed. 50, 2742 (2011).

107. A.I. Abdulagatov, R.A. Hall, J.L. Sutherland, B.H. Lee, A.S. Cavanagh, and S.M. George: Molecular layer deposition of titanicone films using $\mathrm{TiCl}_{4}$ and ethylene glycol or glycerol: Growth and properties. Chem. Mater. 24, 2854 (2012).

108. B.H. Lee, B. Yoon, V.R. Anderson, and S.M. George: Alucone alloys with tunable properties using alucone molecular layer deposition and $\mathrm{Al}_{2} \mathrm{O}_{3}$ atomic layer deposition. J. Phys. Chem. C 116, 3250 (2012)

109. P. Waters and A.A. Volinsky: Stress and moisture effects on thin film buckling delamination. Exp. Mech. 47, 163 (2007).

110. M. Park, S. Oh, H. Kim, D. Jung, D. Choi, and J-S. Park: Gas diffusion barrier characteristics of $\mathrm{Al}_{2} \mathrm{O}_{3}$ /alucone films formed using trimethylaluminum, water and ethylene glycol for organic light emitting diode encapsulation. Thin Solid Films 546, 153 (2013).

111. D.C. Miller, R.R. Foster, S-H. Jen, J.A. Bertrand, D. Seghete, B. Yoon, Y-C. Lee, S.M. George, and M.L. Dunn: Thermomechanical properties of aluminum alkoxide (alucone) films created using molecular layer deposition. Acta Mater. 57, 5083 (2009).

112. D.C. Miller, R.R. Foster, Y. Zhang, S-H. Jen, J.A. Bertrand, Z. Lu, D. Seghete, J.L. O'Patchen, R. Yang, Y-C. Lee, S.M. George, and M.L. Dunn: The mechanical robustness of atomic-layer- and molecular-layer-deposited coatings on polymer substrates. J. Appl. Phys. 105, 093527 (2009).

113. S. Feng-Bo, D. Yu, Y. Yong-Qiang, C. Ping, D. Ya-Hui, W. Xiao, Y. Dan, and X. Kai-wen: Fabrication of tunable $\left[\mathrm{Al}_{2} \mathrm{O}_{3}\right.$ :alucone $]$ thin-film encapsulations for top-emitting organic light-emitting diodes with high performance optical and barrier properties. Org. Electron. 15, 2546 (2014).

114. W. Xiao, D.Y. Hui, C. Zheng, D. Yu, Y. Yong Qiang, C. Ping, C.L. Xiang, and Z. Yi: A flexible transparent gas barrier film employing the method of mixing ALD/MLD-grown $\mathrm{Al}_{2} \mathrm{O}_{3}$ and alucone layers. Nanoscale Res. Lett. 10, 130 (2015).

115. K.H. Yoon, H.S. Kim, K.S. Han, S.H. Kim, Y-E.K. Lee, N.K. Shrestha, S.Y. Song, and M.M. Sung: Extremely high barrier performance of organic-inorganic nanolaminated thin films for organic light-emitting diodes. ACS Appl. Mater. Interfaces 9, 5399 (2017).

116. Z. Chen, H. Wang, X. Wang, P. Chen, Y. Liu, H. Zhao, Y. Zhao, and Y. Duan: Low-temperature remote plasma 
enhanced atomic layer deposition of $\mathrm{ZrO}_{2}$ /zircone nanolaminate film for efficient encapsulation of flexible organic light-emitting diodes. Sci. Rep. 7, 40061 (2017).

117. G.N. Parsons, S.E. Atanasov, E.C. Dandley, C.K. Devine, B. Gong, J.S. Jur, K. Lee, C.J. Oldham, Q. Peng, J.C. Spagnola, and P.S. Williams: Mechanisms and reactions during atomic layer deposition on polymers. Coord. Chem. Rev. 257, 3323 (2013)

118. M-H. Tsai, H-Y. Wang, H-T. Lu, I.H. Tseng, H-H. Lu, S-L. Huang, and J-M. Yeh: Properties of polyimide $/ \mathrm{Al}_{2} \mathrm{O}_{3}$ and $\mathrm{Si}_{3} \mathrm{~N}_{4}$ deposited thin films. Thin Solid Films 519, 4969 (2011).

119. C.A. Wilson, R.K. Grubbs, and S.M. George: Nucleation and growth during $\mathrm{Al}_{2} \mathrm{O}_{3}$ atomic layer deposition on polymers. Chem. Mater. 17, 5625 (2005).

120. L. Lee, K.H. Yoon, J.W. Jung, H.R. Yoon, H. Kim, S.H. Kim, S.Y. Song, K.S. Park, and M.M. Sung: Ultra gas-proof polymer hybrid thin layer. Nano Lett. 18, 5461 (2018).

121. K. Kwak, K. Cho, and S. Kim: Analysis of thermal degradation of organic light-emitting diodes with infrared imaging and impedance spectroscopy. Opt. Express 21, 29558 (2013).

122. J.W. Park, D.C. Shin, and S.H. Park: Large-area OLED lightings and their applications. Semicond. Sci. Technol. 26, 034002 (2011).

123. J.H. Kwon, S. Choi, Y. Jeon, H. Kim, K.S. Chang, and

K.C. Choi: Functional design of dielectric-metal-dielectric-based thin-film encapsulation with heat transfer and flexibility for flexible displays. ACS Appl. Mater. Interfaces 9, 27062 (2017).

124. T-H. Han, Y. Lee, M-R. Choi, S-H. Woo, S-H. Bae: B.H. Hong, J-H. Ahn, and T-W. Lee: Extremely efficient flexible organic light-emitting diodes with modified graphene anode. Nat. Photonics 6, 105 (2012).

125. X. Li, Y. Zhu, W. Cai, M. Borysiak, B. Han, D. Chen, R.D. Piner, L. Colombo, and R.S. Ruoff: Transfer of large-area graphene films for high-performance transparent conductive electrodes. Nano Lett. 9, 4359 (2009).

126. M.S.H. Boutilier, C. Sun, and S.C. O'Hern, H. Au, N.G. Hadjiconstantinou, and R. Karnik: Implications of permeation through intrinsic defects in graphene on the design of defect-tolerant membranes for gas separation. ACS Nano 8, 841 (2014).

127. H-K. Seo, M-H. Park, Y-H. Kim, S-J. Kwon, S-H. Jeong, and T-W. Lee: Laminated graphene films for flexible transparent thin film encapsulation. ACS Appl. Mater. Interfaces 8, 14725 (2016).

128. T. Nam, Y.J. Park, H. Lee, I-K. Oh, J-H. Ahn, S.M. Cho, H. Kim, and H-B-R Lee: A composite layer of atomic-layerdeposited $\mathrm{Al}_{2} \mathrm{O}_{3}$ and graphene for flexible moisture barrier. Carbon 116, 553 (2017).

129. A. Singh, H. Klumbies, U. Schröder, L. Müller-Meskamp, M. Geidel, K. Martin, C. Hoßbach, M. Albert, K. Leo, and T. Mikolajick: Barrier performance optimization of atomic layer deposited diffusion barriers for organic light emitting diodes using X-ray reflectivity investigations. Appl. Phys. Lett. 103, 233302 (2013)
130. A. Singh, F. Nehm, L. Müller-Meskamp, C. Hoßbach, M. Albert, U. Schroeder, K. Leo, and T. Mikolajick: OLED compatible water-based nanolaminate encapsulation systems using ozone based starting layer. Org. Electron. 15, 2587 (2014).

131. J.E. Knox, M.D. Halls, H.P. Hratchian, and H.B. Schlegel Chemical failure modes of $\mathrm{AlQ}_{3}$-based OLEDs: $\mathrm{AlQ}_{3}$ hydrolysis. Phys. Chem. Chem. Phys. 8, 1371 (2006).

132. K. Takeuchi, Y. Ezoe, K. Ishikawa, M. Numazawa, M. Terada, D. Ishi, M. Fujitani, M.J. Sowa, T. Ohashi, and K. Mitsuda: Pt thermal atomic layer deposition for silicon X-ray micropore optics. Appl. Opt. 57, 3237 (2018).

133. T. Maindron, J-Y. Simon, E. Viasnoff, and D. Lafond: Stability of 8-hydroxyquinoline aluminum films encapsulated by a single $\mathrm{Al}_{2} \mathrm{O}_{3}$ barrier deposited by low temperature atomic layer deposition. Thin Solid Films 520, 6876 (2012)

134. A. Gschwandtner: Production worthy ALD in batch reactors. Mater. Sci. Forum 573, 181 (2008).

135. T. Suntola and J. Antson: Method for producing compound thin films. US Patent No. 4058 430, 1977.

136. T.S. Suntola, A.J. Pakkala, and S.G. Lindfors: Apparatus for performing growth of compound thin films. US Patent No. 4389 973, 1983.

137. H. Choi, S. Shin, Y. Choi, Y. Choi, J. Kim, S. Kim, H. Kim, J. Park, S.C. Chung, H. Jeon, and K. Oh: 71.1: High throughput and scalable spatial atomic layer deposition of $\mathrm{Al}_{2} \mathrm{O}_{3}$ as a moisture barrier for flexible OLED display SID. Symp. Dig. Tech. Pap. 46, 1043 (2015).

138. X. Wang, Y. Li, J. Lin, B. Shan, and R. Chen: Modular injector integrated linear apparatus with motion profile optimization for spatial atomic layer deposition. Rev. Sci. Instrum. 88, 115108 (2017).

139. K. Sharma, R.A. Hall, and S.M. George: Spatial atomic layer deposition on flexible substrates using a modular rotating cylinder reactor. J. Vac. Sci. Technol., A 33, 01A132 (2014).

140. P. Poodt, A. Lankhorst, F. Roozeboom, K. Spee, D. Maas, and A. Vermeer: High-speed spatial atomic-layer deposition of aluminum oxide layers for solar cell passivation. Adv. Mater. 22, 3564 (2010).

141. F. Souren, X. Gay, B. Dielissen, and R. Görtzen: Upgrade of an industrial Al-BSF solar cell line into PERC using spatial ALD $\mathrm{Al}_{2} \mathrm{O}_{3}$. In 32nd European photovoltaic solar energy Conference and Exhibition 2BV.7.38 (2016); p. 946.

142. P. Poodt, D.C. Cameron, E. Dickey, S.M. George, V. Kuznetsov, G.N. Parsons, F. Roozeboom, G. Sundaram, and A. Vermeer: Spatial atomic layer deposition: A route towards further industrialization of atomic layer deposition. J. Vac. Sci. Technol., A. 30, 010802 (2011).

143. A. Illiberi, F. Roozeboom, and P. Poodt: Spatial atomic layer deposition of zinc oxide thin films. ACS Appl. Mater. Interfaces. 4, 268 (2012) 
144. D.H. Levy, D. Freeman, S.F. Nelson, P.J. Cowdery-Corvan, and L.M. Irving: Stable $\mathrm{ZnO}$ thin film transistors by fast open air atomic layer deposition. Appl. Phys. Lett. 92, 192101 (2008).

145. P. Poodt, R. Knaapen, A. Illiberi, F. Roozeboom, and A. van Asten: Low temperature and roll-to-roll spatial atomic layer deposition for flexible electronics. J. Vac. Sci. Technol., A 30, 01A142 (2011).

146. C. Ozgit, I. Donmez, M. Alevli, and N. Biyikli: Self-limiting lowtemperature growth of crystalline AlN thin films by plasmaenhanced atomic layer deposition. Thin Solid Films 520, 2750 (2012).
147. M. Bosund, T. Sajavaara, M. Laitinen, T. Huhtio, M. Putkonen, V-M. Airaksinen, and H. Lipsanen: Properties of AlN grown by plasma enhanced atomic layer deposition. Appl. Surf. Sci. 257, 7827 (2011).

148. M. Gebhard, L. Mai, L. Banko, F. Mitschker, C. Hoppe, M. Jaritz, D. Kirchheim, C. Zekorn, T. de los Arcos, D. Grochla, R. Dahlmann, G. Grundmeier, P. Awakowicz, A. Ludwig, and A. Devi: PEALD of $\mathrm{SiO}_{2}$ and $\mathrm{Al}_{2} \mathrm{O}_{3}$ thin films on polypropylene: Investigations of the film growth at the interface, stress, and gas barrier properties of dyads. ACS Appl. Mater. Interfaces 10, 7422 (2018). 